\title{
Optimal Default and Liquidation with Tangible Assets and Debt Renegotiation
}

\author{
Makoto Goto* $\quad$ Masaaki Kijima ${ }^{\dagger} \quad$ Teruyoshi Suzuki ${ }^{\ddagger}$ \\ Second draft: October 6, 2010
}

\begin{abstract}
This paper proposes a new pricing model for corporate securities issued by a levered firm with the possibility of debt renegotiation. We take the structural approach that the firm's earnings follow a geometric Brownian motion with stochastic collaterals. While equity holders can default the firm for their own benefits when the earnings become insufficient to go on the firm, they may want to liquidate it by repaying the face value of debt to debt holders in order to get enough residuals, when the value of collaterals becomes sufficiently high. Unlike the existing theoretical models, the bivariate structure enables us to distinguish strategic default, liquidity default and the ordinary liquidation. It is shown that liquidity default and liquidation possibly occur without entering debt renegotiation, which makes the contribution of strategic debt service to credit spreads lower than that obtained in the previous models, irrespective of the equity holders' bargaining power. Our model resolves the inconsistency reported in recent empirical studies.
\end{abstract}

Keywords: Structural model; Debt renegotiation; Strategic debt service; Credit spread; Liquidity default; Strategic default; Liquidation; M\&A

JEL classifications: D81; G32; G33; G35

\section{Introduction}

The purpose of this paper is to propose a new pricing model for corporate securities issued by a levered firm with the possibility of debt renegotiation. We take the structural approach that the firm's earnings follow a geometric Brownian motion (GBM for short) with stochastic collaterals. As in Leland (1994), equity holders can default the firm for their own benefits, when the earnings become insufficient to go on the firm. In addition, equity holders may want to liquidate the firm by repaying the face value of debt to debt holders in order to get enough residuals, when the

\footnotetext{
${ }^{*}$ Graduate School of Economics and Business Administration, Hokkaido University.

${ }^{\dagger}$ Graduate School of Social Sciences, Tokyo Metropolitan University.

${ }^{\ddagger}$ Corresponding Author. Graduate School of Economics and Business Administration, Hokkaido University. Address: Kita 9, Nishi 7, Kita-ku, Sapporo 060-0809, Japan. E-mail: suzuki@econ.hokudai.ac.jp
} 
value of collaterals becomes sufficiently high. Unlike the existing structural models, the bivariate structure of our model can not only capture realistic credit spreads observed in the market, but also explain many empirical findings reported in the literature.

There are two major approaches for the pricing of corporate securities in the finance literature. The first approach, called the structural approach, ${ }^{1}$ considers a firm's asset value and defines default as occurring either at maturity (as in Merton, 1974) or when the underlying process reaches a default boundary for the first time (as in Black and Cox, 1976; Brennan and Schwartz, 1984). An attractive feature of this approach is that we can analyze how firm-specific variables influence security values. Also, it can treat complex contingent claims written on the firm's asset value (see, e.g., Kijima and Suzuki, 2001). However, if the underlying process follows a diffusion process for the sake of analytical tractability, the model generates only unrealistic credit spreads.

An important development in the structural approach was made in a seminal paper by Leland (1994), who considers the optimal capital structure of a firm based on the balancing theory, i.e., the trade-off between default costs and tax benefits. Assuming that the firm's asset value follows a GBM and corporate securities are contingent claims written on the asset value, Leland (1994) derived the optimal default boundary and the equity value simultaneously by solving a free-boundary problem, because the default boundary is chosen by equity holders so as to maximize the equity value. The debt and total firm values are calculated accordingly. The optimal coupon rate (and hence credit spread) is then determined so as to maximize the total firm value.

However, as Mella-Barral (1999) pointed out, credit spreads calculated by the Leland model are close to those observed in the market only for significantly high default costs. Also, Eom et al. (2004) noted that the models by Merton (1974) and Geske (1977) underestimate the credit spreads, while the models by Longstaff and Schwartz (1995), Leland and Toft (1996) and Collin-Dufresne and Goldstein (2001) overestimate. Since then, several attempts have been made to overcome the deficiency in the structural approach. Among them, Anderson and Sundaresan (1996) and Mella-Barral and Perraudin (1997) proposed a structural model with debt renegotiation. In reality, debt is renegotiated, because liquidation is costly and debt holders cannot suffer from liquidation. Hence, equity holders have an incentive to renegotiate in order to reduce the contractual debt service.

Following Anderson and Sundaresan (1996) and Mella-Barral and Perraudin (1997), Mella-Barral (1999) considered a model with departures from absolute priority rule, while Fan and Sundaresan (2000) incorporated the medium bargaining power and provided the Nash bargaining solution. Structural pricing models with debt renegotiation suggest that, when creditors have little bargaining power, a large part of credit spreads may be due to the possibility of strategic default risk. Debt

\footnotetext{
${ }^{1}$ The other approach, called the reduced-form approach, assumes an exogenous hazard rate process as given, which represents the likelihood of unexpected default of the firm. Major advantages of this approach are its analytical tractability and ability of generating a flexible and realistic term structure of credit spreads. However, since default mechanism is not related to the firm value, we cannot examine the impact of firm-specific variables on the values of corporate securities.
} 
renegotiation by strategic debt service provides higher credit spreads, whereby the models mentioned above succeed to generate realistic credit spreads.

However, recent empirical studies such as Davydenko and Strebulaev (2007) pointed out that the contribution of strategic debt service to credit spreads suggested by the theoretical models is too large. In fact, Davydenko and Strebulaev (2007) found that bond prices do appear to be affected by the possibility of debt renegotiation, while their quantitative contribution to both the average level and the cross-sectional level of credit spreads is below transactions costs. ${ }^{2}$ Based on this result, they are inclined to suggest that debt holders are likely to have significant bargaining power, which limits equity holders' strategic behavior. Also, Acharya et al. (2006) introduced the additional option that firms can carry cash reserves as protection against costly liquidation and concluded that debt renegotiation typically has a negligible effect on the yield spreads under the model of Anderson and Sundaresan (1996).

There is another defect in the theoretical models mentioned above. As Hart and Moore $(1994,1998)$ emphasize, it is important to distinguish strategic default from liquidity default. While liquidity default occurs when the firm's cash flows are insufficient to cover the debt service, strategic default occurs when the firm fails to pay full amount of debt service in debt contract even though it possesses the resource to do so. Most of the papers in the debt renegotiation literature distinguish strategic default from liquidation, but neglect liquidity default. ${ }^{3}$ Moreover, in those models, model parameters determine which occurs, either liquidation or strategic default, in advance. In other words, we know a priori whether or not debt renegotiation eventually occur by looking at the parameter values, and there is no uncertainty how the firm terminates in the future.

In this paper, we extend the existing models to the bivariate framework by introducing the value of tangible assets, which plays the role of collaterals. Because of the bivariate feature, we can distinguish strategic default, liquidity default and the ordinary liquidation. It is shown that, in our model, liquidity default can occur when the value of collaterals is relatively high but the value of earnings (more precisely, earnings before interest and tax; EBIT for short) is substantially low, irrespective of the bargaining power of equity holders. In this case, the firm must pay large maintenance costs for tangible assets despite of the poor business performance, and equity holders cannot afford to carry out the debt contract, resulting in liquidity default. When the value of tangible assets is sufficiently high and the EBIT is substantially low, our model selects liquidation, because equity holders want to repay the face value of debt to debt holders in order to get enough residuals. Otherwise, the firm terminates as strategic default; however, the pattern depends on the sample path of the bivariate process, not the initial parameter values. This means that equity holders can select either liquidity default or liquidation, depending on the economical condition, without entering debt renegotiation. This is a significant

\footnotetext{
${ }^{2}$ Davydenko and Strebulaev (2007) also found the fact that the bond prices are likely to be affected by the possibility of debt renegotiation, especially when the costs of liquidation are likely to be high and credit quality of the issuer is relatively low.

${ }^{3}$ Fan and Sundaresan (2000) consider liquidity default; however, it means liquidation by impossibility of coupon payment, which is basically the same as liquidation considered in other papers.
} 
difference between our model and the other existing models in the debt renegotiation literature.

The possibility of liquidity default and liquidation without entering debt renegotiation is quite important from the pricing perspectives. If renegotiation always occurs in a given model, the effect of strategic debt service will be overstated and its contribution to credit spreads evaluated from the model becomes too high, which can explain the empirical findings in Davydenko and Strebulaev (2007). In fact, our model can produce credit spreads consistent with the empirical findings even when equity holders have full bargaining power, as expected. The contribution of strategic debt service to default premium depends on the underlying variables, in contrast to the existing models such as Mella-Barral and Perraudin (1997).

The rest of the paper is organized as follows. Section 2 describes our two-factor structural model and provides the security values of an unlevered/levered firm without debt renegotiation. In Section 3, we introduce debt renegotiation by strategic debt service to the bivariate model and show some numerical results. Section 4 gives some discussions about extensions of the model, and Section 5 concludes this paper. For the reader's convenience, we provide concise proofs of known (but not trivial) results in Appendix A. Appendix B demonstrates that the results in one-factor models (in particular, the results in Mella-Barral and Perraudin, 1997) can be derived as a special case of our model, showing that our model is indeed an extension of the existing models. Appendix $\mathrm{C}$ is devoted to explain the numerical technique used to solve the bivariate free-boundary problems in this paper.

\section{Debt and Agency Costs}

We consider a firm with a set of tangible (or physical) assets that can yield revenues. Both the value of tangible assets, $V$, and the firm's EBIT (earnings before interest and tax), $P$, are modeled with correlation in a dynamic setting. ${ }^{4}$ The instantaneous risk-free interest rate is assumed to be constant and denoted by $r$. Since we focus on the change of default strategy by introducing stochastic collaterals rather than the capital structure, we neglect the tax benefit and assume that corporate tax rate is zero for simplicity.

\subsection{Basic Assumptions}

Suppose that the asset value $V$ follows a geometric Brownian motion (GBM):

$$
\frac{\mathrm{d} V(t)}{V(t)}=\mu_{v} \mathrm{~d} t+\sigma_{v} \mathrm{~d} B_{1}(t), \quad V(0)=v
$$

where $\mu_{v}$ is the instantaneous expected growth rate of $V, \sigma_{v}$ is the associated volatility, and $B_{1}$ is a standard Brownian motion. The asset needs to be maintained by

\footnotetext{
${ }^{4}$ Many papers such as Mella-Barral and Perraudin (1997) and Mella-Barral (1999) consider a single state variable that is supposed to be positively correlated to revenues. In this paper, we explicitly consider both tangible assets and revenues with correlation.
} 
expending a proportional cost $\eta V .^{5}$

On the other hand, the firm's EBIT $P$ is assumed to follow another GBM:

$$
\frac{\mathrm{d} P(t)}{P(t)}=\mu_{p} \mathrm{~d} t+\sigma_{p} \mathrm{~d} B_{2}(t), \quad P(0)=p,
$$

where $\mu_{p}$ is the instantaneous expected growth rate of $P, \sigma_{p}$ is the volatility, and $B_{2}$ is another standard Brownian motion with instantaneous correlation $\mathbb{E}\left[\mathrm{d} B_{1} \mathrm{~d} B_{2}\right]=$ $\rho \mathrm{d} t{ }^{6}$

Note that our model can be seen as a bivariate extension of existing models in the literature. For example, if we replace the asset value $V$ and the firm's EBIT $P$ by a constant scrap value $\gamma$ and earnings $p-w$, respectively, and neglect the maintenance $\operatorname{cost} \eta V$ of tangible assets, then our model is reduced to the one considered in MellaBarral and Perraudin (1997). Appendix B demonstrates that our model is indeed an extension of Mella-Barral and Perraudin (1997).

Throughout the paper, we assume that $\mu_{v}, \mu_{p}<r$ in order to ensure the existence of value functions of interest. Furthermore, for a levered firm, we assume the following.

Assumption 1 (Levered Firm) The firm issues a perpetual debt with contractual coupon rate $c$, face value $c / r$ and collateral $\underline{C}(t)=\min \{V(t), c / r\}$. Moreover,

1. Equity holders can voluntarily default the firm. Upon default, debt holders own the residual assets and take over the firm as existing equity holders.

2. Equity holders can liquidate the firm's tangible assets and repay the collateral to debt holders. In this case, the firm cannot go on.

3. The firm cannot redeem the debt. That is, the firm cannot turn back to a pure equity firm unless it experiences a default.

Hence, equity holders have options either to default or to liquidate the firm, depending on the state of the variables $(V, P)$. If the firm is defaulted, debt holders take over the firm and it becomes a pure equity firm. If the firm is liquidated, debt holders receive the collateral $\underline{C}$ and equity holders will get the residual. Note that, after the firm becomes a pure equity firm, debt holders can liquidate the firm either immediately or after some time, depending on the state of the variables $(V, P)$. We shall explain how default and liquidation occur in this setting later.

We assume that the liquidation of the firm's tangible asset is induced by M\&A. As pointed out by Lambrecht and Myers (2007), liquidation is often accompanied by (and apparently forced by) M\&A in declining industries. Let $Y(t)$ be the buyout price at time $t$, and suppose that the M\&A market is perfectly competitive and equity holders have full bargaining power against all the raiders. Then, under these

\footnotetext{
${ }^{5}$ As we explain later, equity holders have an incentive to supply short-term funds by increase in capital even if the EBIT is substantially low.

${ }^{6}$ Throughout this paper, we fix the probability space $(\Omega, \mathcal{F}, \mathbb{P})$ and denote the expectation operator by $\mathbb{E}$. The canonical filtration generated by the underlying stochastic structure is denoted by $\left\{\mathcal{F}_{t}\right\}$, where $\mathcal{F}_{t}$ defines the information available at time $t$.
} 
assumptions, the raiders' return is given by $V(t)-\underline{C}(t)-Y(t)=0$ and the M\&A occurs at the best time for equity holders. ${ }^{7}$ In other words, the liquidation can occur at the value

$$
Y(\tau)=V(\tau)-\underline{C}(\tau)
$$

for any stopping time $\tau$.

Because this assumption is essential for the valuation of corporate securities, we state it formally as the following assumption.

Assumption 2 (Liquidation and M\&A) The liquidation of the firm's tangible asset is induced by MEA, where the MEA market is perfectly competitive and equity holders have full bargaining power against all the raiders. The value of the firm's tangible asset upon liquidation is given by (1) for any stopping time $\tau$.

\subsection{Pure Equity Firm}

Before preceding, we first consider a pure equity firm as a benchmark to the levered firm. To do so, we denote by $W^{*}$ the equity value of the firm without debts (hence, $W^{*}$ is equal to the firm value). Note that equity holders can receive the EBIT $P$ minus the maintenance cost $\eta V$ as dividends. Hence, they will liquidate the firm against either a decrease in profits or defrayment of maintenance cost, and upon liquidation, they receive $V$ as the liquidation payoff.

Suppose that $P(0)=p$ and $V(0)=v$, and consider the value function $W^{*}(p, v)$ of the pure equity firm. Let $\tau_{0}$ be the liquidation time chosen by equity holders to maximize their own value. The value function is given by

$$
W^{*}(p, v)=\sup _{\tau_{0} \in \mathcal{T}_{0}} \mathbb{E}\left[\int_{0}^{\tau_{0}} \mathrm{e}^{-r t}(P(t)-\eta V(t)) \mathrm{d} t+\mathrm{e}^{-r \tau_{0}} V\left(\tau_{0}\right)\right],
$$

where $\mathcal{T}_{0}$ denotes the set of admissible stopping times in $[0, \infty)$.

In order to preclude arbitrage opportunities, it is well known that the following equilibrium condition must hold:

$$
r W^{*}=p-\eta v+\mathbb{E}\left[\frac{\mathrm{d} W^{*}}{\mathrm{~d} t}\right] .
$$

Hence, applying Ito's formula, we obtain the partial differential equation (PDE for short)

$$
\mathcal{A} W^{*}(p, v)+p-\eta v=0
$$

where the partial differential operator $\mathcal{A}$ is defined by

$$
\mathcal{A} W^{*}(p, v)=\frac{1}{2} p^{2} \sigma_{p}^{2} W_{p p}^{*}+\frac{1}{2} v^{2} \sigma_{v}^{2} W_{v v}^{*}+p v \sigma_{p} \sigma_{v} \rho W_{p v}^{*}+\mu_{p} p W_{p}^{*}+\mu_{v} v W_{v}^{*}-r W^{*}
$$

Note that the PDE (3) has no constant term and the payoff can be represented in terms of $p / v$ only. Hence, we can find the value function $W^{*}(p, v)$ analytically by using the change-of-variable $z=p / v$. The proof of the next result is standard; however, for the reader's convenience, we provide a concise proof in Appendix A.1.

\footnotetext{
${ }^{7}$ It is an interesting problem to discuss the M\&A under the assumption that raiders choose the acquisition timing so as to maximize their return under imperfect competition. We leave this interesting problem as a future work.
} 
Proposition 1 (Pure Equity Firm) The value function of the pure equity firm is given by

$$
W^{*}(p, v)= \begin{cases}\frac{p}{r-\mu_{p}}-\frac{\eta v}{r-\mu_{v}}+\frac{\left(r-\mu_{v}+\eta\right) v}{(1-\lambda)\left(r-\mu_{v}\right)}\left(\frac{p}{b^{*} v}\right)^{\lambda}, & \text { for } \frac{p}{v}>b^{*} \\ v, & \text { for } \frac{p}{v} \leq b^{*}\end{cases}
$$

where $\lambda$ is the negative root of the quadratic equation

$$
\frac{1}{2} \sigma_{z}^{2} \lambda(\lambda-1)+\left(\mu_{p}-\mu_{v}\right) \lambda-\left(r-\mu_{v}\right)=0
$$

with $\sigma_{z}^{2}=\sigma_{p}^{2}+\sigma_{v}^{2}-2 \rho \sigma_{p} \sigma_{v}$. The optimal liquidation time is obtained as

$$
\tau_{0}^{*}=\inf \left\{t \geq 0: P(t) / V(t) \leq b^{*}\right\},
$$

where the liquidation threshold is given by

$$
b^{*}=\frac{\lambda}{\lambda-1} \frac{r-\mu_{p}}{r-\mu_{v}}\left(r-\mu_{v}+\eta\right) .
$$

The variable $z=p / v$ can be interpreted as the return on tangible assets (ROTA). According to Proposition 1, the pure equity firm will continue its operation as long as ROTA stays above the threshold $b^{*}$. When ROTA goes down to the threshold $b^{*}$, the pure equity firm is liquidated and equity holders receive the value $v$ of tangible assets.

\subsection{Equity Value of the Levered Firm}

This section derives the equity value of the levered firm under Assumption 1. In our setting, equity holders can select one of the two stopping times, default time $\tau_{1}$ or liquidation time $\tau_{2}$, so as to maximize their equity value. Recall from the second statement in Assumption 1 that equity holders can repay the collateral to debt holders and receive the residual upon liquidation. On the other hand, they will receive nothing if the firm is defaulted.

In order to make the difference between the levered firm and the pure equity firm explicit, we denote the value functions of the levered firm by using a hat. ${ }^{8}$ For example, the equity value of the levered firm is denoted by $\hat{F}(p, v)$. Under Assumption 1, the equity value is given by

$$
\begin{aligned}
\hat{F}(p, v)=\sup _{\tau_{1}, \tau_{2} \in \mathcal{T}} \mathbb{E}\left[\int_{0}^{\tau_{1} \wedge \tau_{2}} \mathrm{e}^{-r t}(P(t)\right. & -\eta V(t)-c) \mathrm{d} t \\
& \left.+1_{\left\{\tau_{1}>\tau_{2}\right\}} \mathrm{e}^{-r \tau_{2}} \max \left\{V\left(\tau_{2}\right)-\underline{C}\left(\tau_{2}\right), 0\right\}\right],
\end{aligned}
$$

where $c$ denotes the coupon payment and $\mathcal{T}$ the set of admissible stopping times in $[0, \infty) \times[0, \infty)$. Note that the optimal stopping times are chosen by looking at

\footnotetext{
${ }^{8}$ In the next section, we shall denote the value functions of a levered firm with the possibility of debt renegotiation with no accent marks.
} 
the state variables $(P, V)$. Also, since liquidation is selected only when the payoff is greater than that of default, we obtain

$$
\max \left\{V\left(\tau_{2}\right)-\underline{C}\left(\tau_{2}\right), 0\right\}=V\left(\tau_{2}\right)-\frac{c}{r}>0 .
$$

Note that, if $V\left(\tau_{2}\right)-c / r=0$, this means default.

Because the underlying process $(P, V)$ is homogeneous both in time and in space and the value function is given by $(7)$, we can divide the whole state space $(0, \infty) \times$ $(0, \infty)$ of $(P, V)$ into the three mutually exclusive regions: ordinary operation $\hat{\mathcal{C}}$, default $\hat{\mathcal{D}}$ and liquidation $\hat{\mathcal{L}}$. Associated with each region is the PDE satisfied by the value function $\hat{F}(p, v)$. That is,

$$
\begin{cases}\hat{F}(p, v)=v-\frac{c}{r}, & \text { for }(p, v) \in \hat{\mathcal{L}} \\ \mathcal{A} \hat{F}(p, v)+p-\eta v-c=0, & \text { for }(p, v) \in \hat{\mathcal{C}} \\ \hat{F}(p, v)=0, & \text { for }(p, v) \in \hat{\mathcal{D}}\end{cases}
$$

where $\mathcal{A}$ is the operator defined by (4).

The three regions in Equation (9) are not yet determined. In other words, we must determine the boundaries between $\hat{\mathcal{C}}$ and $\hat{\mathcal{L}}$ and between $\hat{\mathcal{C}}$ and $\hat{\mathcal{D}}$ simultaneously when we solve the PDE (9). Hence, our problem is the so-called free-boundary problem in the two-dimensional setting.

It is well known (see, e.g., Fleming and Soner, 1993) that a function satisfying the PDE (9) as well as the value-matching and smooth-pasting conditions is the value function $\hat{F}(p, v)$. More specifically, denote the boundary between $\hat{\mathcal{C}}$ and $\hat{\mathcal{L}}$ by $\hat{\mathcal{B}}_{C L}$. Then, the value-matching condition is given by

$$
\hat{F}(p, v)=v-\frac{c}{r}, \quad(p, v) \in \hat{\mathcal{B}}_{C L},
$$

and the smooth-pasting condition is stated as

$$
\hat{F}_{p}(p, v)=0, \quad \hat{F}_{v}(p, v)=1, \quad(p, v) \in \hat{\mathcal{B}}_{C L} .
$$

For the boundary $\hat{\mathcal{B}}_{C D}$ between $\hat{\mathcal{C}}$ and $\hat{\mathcal{D}}$, the following conditions hold:

$$
\hat{F}(p, v)=0, \quad \hat{F}_{p}(p, v)=0, \quad \hat{F}_{v}(p, v)=0, \quad(p, v) \in \hat{\mathcal{B}}_{C D}
$$

The PDE (9) must be solved under these conditions.

The difficulty to solve the PDE (9) arises in our setting. Because of the constant coupon rate $c$, we cannot apply the change-of-variable method, $z=p / v$, which was successfully used in the pure equity case (i.e., $c=0$ ). In the following numerical examples, we solve the PDE (9) with value-matching and smooth-pasting conditions by using a finite difference method. To this end, it is helpful to obtain the boundary conditions for $\hat{F}(p, v)$ when $p$ and/or $v$ tend to either 0 or infinity. The importance of these results in the numerical analyses will become clear later. 


\subsubsection{The case that $p$ and/or $v$ are sufficiently large}

Suppose that $p$ and/or $v$ are sufficiently large. Then, because the coupon rate $c$ is a constant, $c / p$ and/or $c / v$ can become negligible, and the PDE (9) coincides asymptotically with the PDE (3) of the pure equity case. Hence, the value function $\hat{F}(p, v)$ is asymptotically given by (5) in Proposition 1 and the boundary $\hat{\mathcal{B}}_{C L}$ approaches to $b^{*}$ for large $v$ and/or $p$.

\subsubsection{The case that $v \rightarrow 0$}

Suppose that the value function $\hat{F}(p, v)$ is sufficiently smooth. Then, when $v \rightarrow 0$, it follows from the PDE (9) that the function $\hat{F}(p, 0+)$ satisfies the ordinary differential equation (ODE for short)

$$
\frac{1}{2} \sigma_{p}^{2} p^{2} \hat{F}_{p p}+\mu_{p} p \hat{F}_{p}-r \hat{F}+p-c=0 .
$$

This is so, because equity holders receive the dividend $p$, pay the coupon $c$, and no maintenance cost $\eta V$, when the tangible asset value $v$ becomes negligible. Also, liquidation never occurs, while default occurs when $p$ goes down to some threshold $\hat{K}$. The next result is standard and the proof is omitted.

Proposition $2 A s v \rightarrow 0$, the equity value $\hat{F}(p, 0+)$ of the levered firm is given by

$$
\hat{F}(p, 0+)= \begin{cases}\frac{p}{r-\mu_{p}}-\frac{c}{r}+\frac{c}{r(1-\beta)}\left(\frac{p}{\hat{K}}\right)^{\beta}, & \text { for } p>\hat{K}, \\ 0, & \text { for } p \leq \hat{K}\end{cases}
$$

where the default threshold is given by

$$
\hat{K}=\frac{\beta}{\beta-1}\left(r-\mu_{p}\right) \frac{c}{r},
$$

and $\beta$ is the negative root of the characteristic quadratic equation

$$
\frac{1}{2} \sigma_{p}^{2} \beta(\beta-1)+\mu_{p} \beta-r=0 .
$$

\subsubsection{The case that $p \rightarrow 0$}

As $p \rightarrow 0$, it follows from the PDE (9) that the function $\hat{F}(0+, v)$ satisfies the ODE

$$
\frac{1}{2} \sigma_{v}^{2} v^{2} \hat{F}_{v v}+\mu_{v} v \hat{F}_{v}-r \hat{F}-\eta v-c=0 .
$$

This is so, because equity holders pay the coupon $c$ and the maintenance cost $\eta v$, even though earnings are zero (i.e., EBIT $p \rightarrow 0$ ).

Note that, in this case, equity holders do not only wait for default, but can also receive the positive residual asset value by liquidating the firm and repaying the debt, if the value of tangible assets, $V$, is sufficiently high. That is, equity holders either liquidate the firm, if $V$ goes up to some upper threshold $\hat{U}$, or default the firm at some lower threshold $\hat{L}$. The proof of the next result is given in Appendix A.2. 
Proposition 3 As $p \rightarrow 0$, the equity value $\hat{F}(0+, v)$ of the levered firm is given by

$$
\hat{F}(0+, v)= \begin{cases}v-\frac{c}{r}, & \text { for } v \geq \hat{U}, \\ A_{1} v^{\gamma_{1}}+A_{2} v^{\gamma_{2}}-\frac{\eta v}{r-\mu_{v}}-\frac{c}{r}, & \text { for } \hat{L}<v<\hat{U} \\ 0, & \text { for } v \leq \hat{L}\end{cases}
$$

where the default threshold $\hat{L}$ and the liquidation threshold $\hat{U}$ are given, respectively, by

$$
\hat{L}=\frac{\gamma_{1} c}{r} /\left\{k^{1-\gamma_{2}}\left(\gamma_{1}-1\right)\left(\frac{r-\mu_{v}+\eta}{r-\mu_{v}}\right)-\frac{\eta\left(\gamma_{1}-1\right)}{r-\mu_{v}}\right\}, \quad \hat{U}=k \hat{L},
$$

with $k>1$ being the root of the equation

$$
\gamma_{2}\left(\gamma_{1}-1\right) k^{1-\gamma_{2}}-\gamma_{1}\left(\gamma_{2}-1\right) k^{1-\gamma_{1}}=\frac{\eta\left(\gamma_{1}-\gamma_{2}\right)}{r-\mu_{v}+\eta}
$$

Here, $\gamma_{1}<0$ and $\gamma_{2}>1$ are the roots of the characteristic quadratic equation

$$
\frac{1}{2} \sigma_{v}^{2} \gamma(\gamma-1)+\mu_{v} \gamma-r=0
$$

and the coefficients $A_{1}$ and $A_{2}$ are given, respectively, by

$$
A_{1}=\frac{\hat{L}^{-\gamma_{1}}}{\gamma_{2}-\gamma_{1}}\left(\frac{\eta \hat{L}\left(\gamma_{2}-1\right)}{r-\mu_{v}}+\gamma_{2} \frac{c}{r}\right), A_{2}=\frac{\hat{L}^{-\gamma_{2}}}{\gamma_{1}-\gamma_{2}}\left(\frac{\eta \hat{L}\left(\gamma_{1}-1\right)}{r-\mu_{v}}+\gamma_{1} \frac{c}{r}\right)
$$

\subsection{Debt and Firm Values of the Levered Firm}

As stated in Assumption 1, debt holders receive coupon payments $c$ until either default epoch $\tau_{1}$ or liquidation time $\tau_{2}$, whichever happens first. If equity holders decide to liquidate before defaulting the firm, debt holders receive the face value $c / r$ at $\tau_{2}$ from Equation (8). On the other hand, if equity holders decide to default the firm, debt holders will take over the firm at $\tau_{1}$ and the firm becomes a pure equity firm. The debt holders will then receive the profit $\xi p$, where $\xi<1$ is the efficiency loss of EBIT $p$, until they liquidate the firm at time $\tau_{3}$. The liquidation time $\tau_{3}$ is determined so as to maximize the value of the pure equity firm.

More specifically, let $X(p, v)$ represent the value of the firm taken over by debt holders, when $P(0)=p$ and $V(0)=v$. Because the firm is a pure equity firm, we can find $X(p, v)$ analytically as

$$
\begin{aligned}
X(p, v) & =\sup _{\tau_{3} \in \mathcal{T}_{0}} \mathbb{E}\left[\int_{0}^{\tau_{3}} \mathrm{e}^{-r t}(\xi P(t)-\eta V(t)) \mathrm{d} t+\mathrm{e}^{-r \tau_{3}} V\left(\tau_{3}\right)\right], \\
& = \begin{cases}\frac{\xi p}{r-\mu_{p}}-\frac{\eta v}{r-\mu_{v}}+\frac{\left(r-\mu_{v}+\eta\right) v}{(1-\lambda)\left(r-\mu_{v}\right)}\left(\frac{p}{b}\right)^{\lambda}, & \text { for } \frac{p}{v}>\underline{b}, \\
v, & \text { for } \frac{p}{v} \leq \underline{b},\end{cases}
\end{aligned}
$$


where $\lambda$ is given as in Proposition 1 and the liquidation threshold is given by

$$
\underline{b}=\frac{\lambda}{\lambda-1} \frac{r-\mu_{p}}{r-\mu_{v}} \frac{r-\mu_{v}+\eta}{\xi}
$$

which should be compared with the threshold given in (6). The debt value is now obtained as

$$
\begin{aligned}
\hat{D}(p, v)= & \sup _{\tau_{3} \in \mathcal{T}_{0}} \mathbb{E}\left[\int_{0}^{\tau_{1} \wedge \tau_{2}} \mathrm{e}^{-r t} c \mathrm{~d} t+\mathbf{1}_{\left\{\tau_{1}>\tau_{2}\right\}} \mathrm{e}^{-r \tau_{2}} \frac{c}{r}\right. \\
& \left.+\mathbf{1}_{\left\{\tau_{1} \leq \tau_{2}\right\}}\left(\int_{\tau_{1}}^{\tau_{3}} \mathrm{e}^{-r t}(\xi P(t)-\eta V(t)) \mathrm{d} t+\mathrm{e}^{-r \tau_{3}} V\left(\tau_{3}\right)\right)\right] \\
= & \mathbb{E}\left[\int_{0}^{\tau_{1} \wedge \tau_{2}} \mathrm{e}^{-r t} c \mathrm{~d} t+\mathbf{1}_{\left\{\tau_{1}>\tau_{2}\right\}} \mathrm{e}^{-r \tau_{2}} \frac{c}{r}+\mathbf{1}_{\left\{\tau_{1} \leq \tau_{2}\right\}} \mathrm{e}^{-r \tau_{1}} X\left(P\left(\tau_{1}\right), V\left(\tau_{1}\right)\right)\right] .
\end{aligned}
$$

Of course, the debt value $\hat{D}(p, v)$ satisfies the following PDE:

$$
\begin{cases}\hat{D}(p, v)=\frac{c}{r}, & \text { for }(p, v) \in \hat{\mathcal{L}} \\ \mathcal{A} \hat{D}(p, v)+c=0, & \text { for }(p, v) \in \hat{\mathcal{C}} \\ \hat{D}(p, v)=X(p, v), & \text { for }(p, v) \in \hat{\mathcal{D}}\end{cases}
$$

Since the boundaries are known, this is not a free-boundary problem and can be solved numerically by, e.g., the ordinary finite difference method. To do that, however, it is helpful to have analytical formulas for its boundary values as $v, p \rightarrow 0$. The next result is similar to Propositions 2 and 3, and the proof is omitted.

Proposition 4 As $v \rightarrow 0$, the debt value is obtained as

$$
\hat{D}(p, 0+)= \begin{cases}\frac{c}{r}-\frac{(\xi-1) \beta+1}{1-\beta} \frac{c}{r}\left(\frac{p}{\hat{K}}\right)^{\beta}, & \text { for } p>\hat{K}, \\ \frac{\xi p}{r-\mu_{p}}, & \text { for } p \leq \hat{K},\end{cases}
$$

where $\beta$ and the default threshold $\hat{K}$ are given as in Proposition 2. As $p \rightarrow 0$, the debt value is given by

$$
\hat{D}(0+, v)= \begin{cases}\frac{c}{r}, & \text { for } v \geq \hat{U}, \\ \frac{c}{r}+B_{1} v^{\gamma_{1}}+B_{2} v^{\gamma_{2}}, & \text { for } \hat{L}<v<\hat{U}, \\ v, & \text { for } v \leq \hat{L},\end{cases}
$$

where

$$
B_{1}=\frac{\hat{L}-c / r}{\hat{L}^{\gamma_{1}}-\hat{L}^{\gamma_{2}} \hat{U}^{\gamma_{1}-\gamma_{2}}}, \quad B_{2}=-B_{1} \hat{U}^{\gamma_{1}-\gamma_{2}}
$$

and where $\gamma_{i}, i=1,2$, the default threshold $\hat{L}$, and the liquidation threshold $\hat{U}$ are given as in Proposition 3. 
Finally, the value of the levered firm is obtained as

$$
\begin{aligned}
\hat{W}(p, v)=\hat{F}(p, v)+\hat{D}(p, v) & \\
=\mathbb{E}\left[\int_{0}^{\tau_{1} \wedge \tau_{2}} \mathrm{e}^{-r t}(P(t)-\eta V(t)) \mathrm{d} t\right. & +1_{\left\{\tau_{1} \leq \tau_{2}\right\}} \mathrm{e}^{-r \tau_{1}} X\left(P\left(\tau_{1}\right), V\left(\tau_{1}\right)\right) \\
& \left.+1_{\left\{\tau_{1}>\tau_{2}\right\}} \mathrm{e}^{-r \tau_{2}} V\left(\tau_{2}\right)\right],
\end{aligned}
$$

where the stopping times $\tau_{1}$ and $\tau_{2}$ are selected by equity holders and $\tau_{3}$ by debt holders. When $p \rightarrow 0$ or $v \rightarrow 0$, we obtain closed-form solutions for $\hat{W}(p, v)$.

Proposition 5 As $v \rightarrow 0$, the firm value is obtained as

$$
\hat{W}(p, 0+)= \begin{cases}\frac{p}{r-\mu_{p}}-\frac{(\xi-1) \beta c}{1-\beta} \frac{c}{r}\left(\frac{p}{\hat{K}}\right)^{\beta}, & \text { for } p>\hat{K}, \\ \frac{\xi p}{r-\mu_{p}}, & \text { for } p \leq \hat{K},\end{cases}
$$

where $\beta$ and the default threshold $\hat{K}$ are given as in Proposition 2. As $p \rightarrow 0$, the firm value is given by

$$
\hat{W}(0+, v)= \begin{cases}v, & \text { for } v \geq \hat{U}, \\ -\frac{\eta v}{r-\mu_{v}}+\left(A_{1}+B_{1}\right) v^{\gamma_{1}}+\left(A_{2}+B_{2}\right) v^{\gamma_{2}}, & \text { for } \hat{L}<v<\hat{U} \\ v, & \text { for } v \leq \hat{L},\end{cases}
$$

where the coefficients $B_{1}, B_{2}$ are given as in Proposition 4 , and where $\gamma_{i}, i=1,2$, the default threshold $\hat{L}$, the liquidation threshold $\hat{U}$, and the coefficients $A_{1}, A_{2}$ are given as in Proposition 3.

Remark 1 If we assume a tax benefit for coupon payments, we can consider the optimal capital structure of the firm as in Leland (1994), where the optimal coupon level is selected so as to maximize the firm value $\hat{W}(p, v)$. However, since the boundaries $\mathcal{B}_{C L}$ and $\mathcal{B}_{C D}$ depend on the model parameters such as coupon rate $c$, in order to obtain the optimal capital structure of the firm, we need to solve the free-boundary problem repeatedly until the firm value is maximized with respect to the coupon rate $c$. This is not an easy numerical problem, although not impossible.

\subsection{Numerical Analyses}

We solve the PDE (9) with value-matching and smooth-pasting conditions (10)(11) by using the finite difference method explained in Appendix C. Unless stated otherwise, we take $750 \times 750$ meshes $^{9}$ with equal spaces on the state space $[0,1] \times[0,1]$ for the transformed variables $(x, y)$; see (C.3). The numerical procedure is very stable.

\footnotetext{
${ }^{9}$ The algorithm presented in Appendix $\mathrm{C}$ is iterative, so that the required CPU time is proportional to the number of meshes $N^{2}$, where $N$ is the number of partitions in each axis.
} 
Table 1: Base Parameters

\begin{tabular}{ccccccccc}
\hline$\sigma_{p}$ & $\sigma_{v}$ & $\mu_{p}$ & $\mu_{v}$ & $\rho$ & $\eta$ & $\xi$ & $r$ & $c$ \\
\hline $30 \%$ & $15 \%$ & $4 \%$ & $2 \%$ & 0.7 & $1 \%$ & 0.7 & $6 \%$ & $8 \%$ \\
\hline
\end{tabular}

The base parameters used in the numerical examples are given in Table 1. Calculation results of the default and liquidation boundaries are depicted in Figure 1, where the horizontal and vertical axes represent $p /\left(r-\mu_{p}\right)$ and $v$, respectively. ${ }^{10}$

[Figure 1 is inserted around here.]

In Figure 1, the dashed line represents the straight line $p / v=b^{*}$ and the chained line represents the straight line $p / v=\underline{b}$. While a pure equity firm is liquidated in the region above the line $p / v=b^{*}$, debt holders liquidate their firm above the line $p / v=\underline{b}$, if they have become new owners of the firm. Note from Equations (6) and (18) that $\underline{b}<b$ due to the efficiency loss $\xi<1$ of EBIT. Moreover, the area surrounded by the curve in the top-left (bottom-left, respectively) corner represents the liquidation region $\hat{\mathcal{L}}$ (default region $\hat{\mathcal{D}}$ ). The other area represents the ordinary operating region $\hat{\mathcal{C}}$. We recognize the liquidation region $\hat{\mathcal{L}}$ to be in the top-left corner from Proposition 3. Similarly, the default region $\hat{\mathcal{D}}$ is located in the bottomleft corner because of the results in Propositions 2 and 3. The point $c / r=1.3333$ is added on the $v$-axis. Note that $\hat{U}=1.4693$ and $\hat{L}=1.2220$ on the $v$-axis, and $\hat{K}=0.01397$ on the $p$-axis in the case of base parameters given in Table 1 .

\subsubsection{Comparison with the one-factor case}

As explained in Appendix B, our model is a bivariate counterpart of the model considered in Mella-Barral and Perraudin (1997). In order to make the significance of our extension clearer, we compare the boundaries and possible sample paths in the two models, and discuss how default and liquidation occur differently.

Figure 2 depicts the calculation results of the one-factor model (see Appendix B), where we set $w=0$ and the other parameters are chosen from Table 1. Although $v$ is just a parameter in the one-factor case, we depict the figure on the $(p, v)$-plane for the sake of comparison. Similar to Figure 1, the dashed and chained lines in Figure 2 represent the straight lines $p / v=b_{1}^{*}$ and $p / v=\underline{b}_{1}$, respectively. These straight lines have different slopes, i.e., $b^{*} \neq b_{1}^{*}$ and $\underline{b} \neq \underline{b}_{1}$, due to the effect of correlation $\rho$ and volatility $\sigma_{v}$ of the stochastic collateral $V$. However, we know that $\hat{K}=\hat{K}_{1}$ if $w=0$ and the boundaries $\hat{U}$ and $\hat{L}$ converge to $c / r$ as $\sigma_{v} \rightarrow 0$. Of course, all the boundaries in Figure 1 converge to those depicted in Figure 2. As a result, the default region $\hat{\mathcal{D}}_{1}$ in the one-factor model becomes a rectangular and the gap between $\hat{\mathcal{D}}_{1}$ and $\hat{\mathcal{L}}_{1}$ (liquidation region) disappears.

[Figure 2 is inserted around here.]

\footnotetext{
${ }^{10}$ To make the boundaries smooth enough, we take $1,000 \times 1,000$ meshes with equal spaces for the calculation of Figures 1, 10 and 19. All the figures in this paper are plotted on the $(p, v)$-plane with the horizontal axis $p /\left(r-\mu_{p}\right)$, the net present value of future EBIT.
} 
In Figures 1 and 2, we add typical sample paths of the process $(P, V)$ in order to explain the default/liquidation mechanism in the two models. Note that the sample paths in Figure 1 start from the same initial value $(p, v)$, while the process $P$ in the one-factor model can move only on the pre-specified horizontal line for a given initial value $v$.

To be more specific, in the one-factor model (see Figure 2), typical sample paths are the following. Starting from the operating region $\hat{\mathcal{C}}_{1}$ with different value of $v$;

1. The process $P$ hits the default region $\hat{\mathcal{D}}_{1}$ before crossing the line $p / v=\underline{b}_{1}$. In this case (sample path (a')), equity holders default and debt holders take over the firm. The firm is operated as a pure equity firm with suffering the efficiency loss $\xi$ of EBIT. After some time, the firm is liquidated when the process $P$ hits the line $p / v=\underline{b}_{1}$. Note that, if the firm started as a pure equity firm, liquidation would occur at the line $p / v=b_{1}^{*}$. Since $\underline{b}_{1}<b_{1}^{*}$ due to the efficiency loss $\xi<1$, the firm taken over by debt holders will be liquidated earlier than the hypothetical pure equity firm. This phenomenon is often called an early liquidation.

2. The process $P$ first crosses the line $p / v=\underline{b}_{1}$ and then touches the default region $\hat{\mathcal{D}}_{1}$. In this case (sample path (b')), equity holders default and debt holders liquidate the firm immediately (they do not take over the firm). Since liquidation occurs before the process $P$ crosses the line $p / v=b_{1}^{*}$, it is also an early liquidation.

3. The process $P$ touches the line $p / v=b_{1}^{*}$ first since $v>c / r$ (i.e., the debt is safe). In this case (sample path (c')), equity holders liquidate tangible assets and repay the face value of debt to debt holders in order to receive the residual.

Hence, there exist only three patterns depending on the initial parameter values, and we know a priori which pattern will occur by looking at the parameters.

In contrast to the one-factor case, there are more patterns in our model and each pattern occurs stochastically, depending on the sample paths of the process $(P, V)$. For example (see Figure 1), starting from the same point $(p, v)$ in the operating region $\hat{\mathcal{C}}$;

1. The process $(P, V)$ hits the default region $\hat{\mathcal{D}}$ below the line $p / v=\underline{b}$. In this case (sample path (a)), equity holders default and debt holders take over the firm. Later, the firm is liquidated when the process $(P, V)$ crosses the line $p / v=\underline{b}$, whence it is an early liquidation.

2. The process $(P, V)$ hits the default region $\hat{\mathcal{D}}$ above the line $p / v=\underline{b}$. In this case (sample paths (b) and (d)), equity holders default and debt holders liquidate the firm immediately (they do not take over the firm). If liquidation occurs before the process $(P, V)$ crosses the line $p / v=b^{*}$ (sample path (b)), it is an early liquidation. On the other hand, if liquidation occurs beyond the line $p / v=b^{*}$ (sample path (d)), it is a late liquidation.

3. The process $(P, V)$ hits the liquidation region $\hat{\mathcal{L}}$ before visiting the default region $\hat{\mathcal{D}}$. In this case (sample path $(\mathrm{c})$ ), equity holders liquidate tangible 
assets and repay the face value of debt to debt holders in order to receive the residual. Since this pattern occurs after the process crosses the line $p / v=b^{*}$, it is a late liquidation.

In the one-factor model such as Mella-Barral and Perraudin (1997) and MellaBarral (1999), there is a possibility that the Modigliani-Miller theorem hold. In particular, if $\xi=1$ in Mella-Barral and Perraudin (1997), the firm value is unchanged when debt is issued. However, in our model, this is not the case because of the possibility of liquidation (sample path (c)). That is, the Modigliani-Miller theorem cannot hold for any parameter set in our model.

To see this, compare Equation (2) with Equations (16) and (20). Then, we recognize that the difference between $W^{*}(p, v)$ and $\hat{W}(p, v)$ comes not only from the difference between $\tau_{0}$ and $\tau_{3}$ but also from the difference between $\tau_{0}$ and $\tau_{2}$. While the former difference is due to the efficiency loss $\xi<1$ of EBIT after debt holders take over the firm, the latter appears because liquidation selected by equity holders does not maximize the total firm value. Hence, if $\xi=1$, we have $\tau_{0}=\tau_{3}$; however, this does not ensure $\tau_{0}=\tau_{2}$, because equity holders can select liquidation for their own. Therefore, as far as the possibility of liquidation (sample path (c)) exists, the firm value decreases when debt is issued, i.e., $W^{*}(p, v)>\hat{W}(p, v)$.

\subsubsection{Significance of tangible assets}

As we have seen through the comparison of the two models, equity holders in our model have two options, either to default or to liquidate the firm, and which option is exercised is determined by the sample paths of the underlying process, i.e., it will happen stochastically. Also, our model admits both early and late liquidations, irrespective of the starting point. Note that these flexibilities are not possible in the one-factor case.

Besides these merits, we can also point out other important features in our model. For example, sample path (d) possibly occurs only when the value of tangible assets is stochastic. To see this, as the volatility $\sigma_{v}$ of tangible assets tends to zero, the gap between default region $\hat{\mathcal{D}}$ and liquidation region $\hat{\mathcal{L}}$ beyond the line $p / v=b^{*}$ shrinks and diminishes. In fact, as we shall see later, sample path (d) can represent liquidity default when debt renegotiation is possible.

When the value of tangible assets is sufficiently high and the EBIT is substantially low, our model selects liquidation (see sample path (d) in Figure 1). As stated in Assumption 2, the liquidation is induced by M\&A (usually in declining industries). Note that the asset value $V$ fluctuates even after the M\&A, depending on economic circumstances. It is possible that $V$ becomes worthless before the EBIT is improved, resulting in a failure of M\&A. Hence, our model can explain M\&A undertaken primarily for liquidation and the possibility of its failure.

Finally, suppose that the value of tangible assets is somewhere in the gap, i.e., the firm is in operation due to enough collaterals although the earnings are substantially low. Then, it is possible for equity holders to supply short-term funds by increase in capital despite of the low earnings. Note that, in the existing literature, the incentive of increase in capital is limited to high earnings and continuation of renegotiation. In 
reality, however, firms with enough collaterals have incentives to increase in capital, as our model suggests.

\subsubsection{Numerical evaluation of security values}

Figure 3 shows the equity value $\hat{F}(p, v)$ as a function of tangible asset value, $v$, and the net present value of future EBIT, $p /\left(\mu_{p}-r\right)$. The lines with squares and circles on the $(p, v)$-plane plot the optimal default and liquidation boundaries, respectively. Since equity holders select these boundaries so as to maximize the equity value, we observe that the equity value is a convex function of $(p, v)$.

[Figure 3 is inserted around here.]

On the other hand, Figure 4 depicts the debt value $\hat{D}(p, v)$. Since we have already derived the boundaries, the debt value can be calculated by solving the PDE (19) using the ordinary finite difference method. ${ }^{11}$ Note from Proposition 4 that both $\hat{D}(p, 0)$ and $\hat{D}(0, v)$ in the region $\hat{\mathcal{C}}$ are strictly concave. ${ }^{12}$ However, the debt value $\hat{D}(p, v)$ is not concave with respect to $(p, v)$ in the region $\hat{\mathcal{C}}$. This is so, because from (20) we can rewrite the total firm value as

$$
\begin{aligned}
\hat{W}(p, v)= & \frac{p}{r-\mu_{p}}-\frac{\eta v}{r-\mu_{v}} \\
& +\mathbb{E}\left[\mathbf{1}_{\left\{\tau_{1} \leq \tau_{2}\right\}} \mathrm{e}^{-r \tau_{1}}\left(X\left(P\left(\tau_{1}\right), V\left(\tau_{1}\right)\right)-\int_{\tau_{1}}^{\infty} \mathrm{e}^{-r t}(P(t)-\eta V(t)) \mathrm{d} t\right)\right. \\
& \left.\quad+\mathbf{1}_{\left\{\tau_{1} \geq \tau_{2}\right\}} \mathrm{e}^{-r \tau_{2}}\left(V\left(\tau_{2}\right)-\int_{\tau_{2}}^{\infty} \mathrm{e}^{-r t}(P(t)-\eta V(t)) \mathrm{d} t\right)\right] .
\end{aligned}
$$

Hence, as observed by Leland (1994), the firm value $\hat{W}(p, v)$ consists of the three terms: the value of business assets (EBIT), the value of default costs, and the value of option to default/liquidate. Recall that equity holders possess options to default or to liquidate, while debt holders do not. Hence, by a similar manner to Leland (1994), we observe that the debt value can be concave and convex, depending on the domain of the state variables $(p, v)$. In fact, the debt value is equal to $X(p, v)$, which is convex in the region $\hat{\mathcal{D}}$, as given in Equation (17).

[Figure 4 is inserted around here.]

Finally, Figure 5 shows the credit spread $c / \hat{D}(p, v)-r$. The numbers labeled on the contour lines represent the credit spreads (bp). The solid and dash-dotted curves plot the optimal default and liquidation boundaries, respectively. The solid

\footnotetext{
${ }^{11}$ Again, we employ the change-of-variable technique (C.3) and perform the finite difference method for the transformed PDE. Although this is not a free-boundary problem, we employ the successive over-relaxations method, because the PDE (19) is elliptical and the system of equations produced by discretization has huge unknowns.

${ }^{12}$ As Black and Scholes (1973) observed, stock is a call option written on the firm's asset with exercise price being equal to the face value of the outstanding debt. The value of debt is equal to the value of firm minus the value of stock. In this case, the concavity of debt value results from the convexity of equity value.
} 
and dotted lines depict the straight lines $p / v=b^{*}$ and $p / v=\underline{b}$, respectively. The parameters are taken from Table 1 . It is observed that a firm with few tangible assets has high credit spreads even if its EBIT is large. Also, even if a firm has enough tangible assets to secure the debt principle $c / r$, its debt is not risk-free, because the value of tangible assets is stochastic. Note that the credit spreads are constant with respect to $p$ in the region that debt holders decide to liquidate after they take over the firm.

[Figure 5 is inserted around here.]

\subsubsection{Agency problems}

Jensen and Meckling (1976) argue that equity holders like to make the firm's activities riskier, ceteris paribus, so as to increase the equity value at the expense of debt value. Because our model has two sources of risk that affect the values of securities and the debt value is not necessarily concave as shown in the previous section, it is particularly important to investigate the impact of risk shifting on equity and debt values.

First, we consider the impact of EBIT volatility $\sigma_{p}$ (business risk) on the equity value. Figure 6 illustrates the impact of $\sigma_{p}$ on its percentage change, i.e.,

$$
\frac{\hat{F}\left(p, v \mid \sigma_{p}=0.4\right)-\hat{F}\left(p, v \mid \sigma_{p}=0.3\right)}{\hat{F}\left(p, v \mid \sigma_{p}=0.3\right)},
$$

which shows the equity holders' incentive to raise the business risk $\sigma_{p}$. As suggested by Jensen and Meckling (1976), equity holders have a strong incentive to raise the business risk even on the brink of default in our model.

[Figure 6 is inserted around here.]

On the other hand, Figure 7 depicts the impact of $\sigma_{p}$ on the percentage change of debt value, i.e.,

$$
\frac{\hat{D}\left(p, v \mid \sigma_{p}=0.4\right)-\hat{D}\left(p, v \mid \sigma_{p}=0.3\right)}{\hat{D}\left(p, v \mid \sigma_{p}=0.3\right)},
$$

which shows the debt holders' incentive to raise the business risk $\sigma_{p}$. Since equity is a residual claim, equity holders gain from the fall of debt value (the asset substitution problem), if the firm value is unchanged. This problem occurs in the bottom-right corner in Figures 6 and 7, although we cannot see it in other areas. In our model, equity holders gain by risk shifting, not because debt holders lose their value, but because the firm value $\hat{W}(p, v)$ increases. Note that, at the brink of default with $v$ being less than unity, both equity holders and debt holders wish to increase the business risk. This anomaly is also observed in Leland (1994). The reason is that the default boundary changes as $\sigma_{p}$ changes, and debt holders wish to be far away from default boundary by increasing the business risk. As we shall see later, this phenomenon has an important role in the analysis of risk shifting when debt renegotiation is considered.

[Figure 7 is inserted around here.] 
Next, we consider the impact of tangible asset volatility $\sigma_{v}$ (collateral risk) on equity value. Figure 8 shows the impact of $\sigma_{v}$ on its percentage change, i.e.,

$$
\frac{\hat{F}\left(p, v \mid \sigma_{v}=0.25\right)-\hat{F}\left(p, v \mid \sigma_{v}=0.15\right)}{\hat{F}\left(p, v \mid \sigma_{v}=0.15\right)} .
$$

We observe that equity holders have a strong incentive to increase risk $\sigma_{v}$ at the brink of default, while they have no incentive when the level of EBIT is sufficiently high. This is so, because the equity value is almost linear with respect to $p$ when $p$ is large. Note that the impact of $\sigma_{p}$ on equity value is especially high in the right side of the default boundary in Figure 6, while the impact of $\sigma_{v}$ is especially high above the default boundary in Figure 8. Hence, on the corner of the default boundary, equity holders have much incentive to raise both risks $\sigma_{p}$ and $\sigma_{v}{ }^{13}$

[Figure 8 is inserted around here.]

Figure 9 shows the impact of $\sigma_{v}$ on the percentage change of debt value, i.e.,

$$
\frac{\hat{D}\left(p, v \mid \sigma_{v}=0.25\right)-\hat{D}\left(p, v \mid \sigma_{v}=0.15\right)}{\hat{D}\left(p, v \mid \sigma_{v}=0.15\right)} .
$$

Unlike Figure 7, debt holders lose their value in the whole region. Note that anomaly at the brink of default does not occur in this risk shifting. This might be a result from the fact that the increase in $\sigma_{v}$ raises the optimal liquidation boundary, which guarantees debt holders to receive the full amount of face value. ${ }^{14}$

[Figure 9 is inserted around here.]

\section{Pricing with Renegotiation}

In this section, we consider the possibility of debt renegotiation as in Anderson and Sundaresan (1996) and Mella-Barral and Perraudin (1997). That is, suppose that debt holders and equity holders can renegotiate about coupon payments each other. Throughout this section, we assume that equity holders have full bargaining power, unless stated otherwise. In the word of Mella-Barral and Perraudin (1997), equity holders can make the 'take-it-or-leave-it' offer to debt holders.

Let $s(p, v)$ denote the service flow function, when strategic debt service is performed. This means that equity holders can offer debt holders a discount of coupon payments instead of default. The offered coupon rate in the state $(p, v)$ is represented by the function $s(p, v)$, which is determined by equity holders, because they have full bargaining power. It is assumed that the service flow function is piecewise right-continuous.

\footnotetext{
${ }^{13}$ The impact of $\sigma_{v}$ is negative at the default boundary with $v \leq 0.5$. This is so, because the boundaries for $\sigma_{v}=0.15$ and $\sigma_{v}=0.25$ cross each other and the equity value for $\sigma_{v}=0.25$ decreases.

${ }^{14}$ Similar to Figure 8, the reason why the impact of $\sigma_{v}$ is negative is that the boundaries for $\sigma_{v}=0.15$ and $\sigma_{v}=0.25$ cross each other and the debt value for $\sigma_{v}=0.25$ decreases.
} 
Under the possibility of debt renegotiation, the equity and debt values are different from those without renegotiation. We denote by $F(p, v)$ and $D(p, v)$, respectively, the equity and debt values under renegotiation. Recall that $X(p, v)$ represents the equity value after debt holders take over the firm.

As default approaches, the debt value $D(p, v)$ becomes strictly larger than $X(p, v)$. Equity holders exploit the difference and offer a discount of coupon until $D(p, v)$ becomes equal to $X(p, v)$. Because debt holders have no bargaining power, they must accept this offer. Hence, the service flow function $s(p, v)$ is determined such that $D(p, v)=X(p, v)$. See Mella-Barral and Perraudin (1997) for details.

As before, we define the three mutually exclusive regions in $(p, v)$ : ordinary operation $\mathcal{C}$, default $\mathcal{D}$, and liquidation $\mathcal{L}$. In addition, we need to define the region in which equity holders carry out the strategic debt service. This region is denoted by $\mathcal{S}$, which is disjoint from the other regions. Hence, under the possibility of debt renegotiation, we have four mutually exclusive regions, $\mathcal{C}, \mathcal{D}, \mathcal{L}$ and $\mathcal{S}$. When the process $(P, V)$ is in $\mathcal{C}$, equity holders pay the contractual coupon $c$. Once $(P, V)$ hits the region $\mathcal{S}$, equity holders offer a discount of coupon instead of default. After that, equity holders default when $(P, V)$ reaches the region $\mathcal{D}$. Summarizing, we assume the following for the case of debt renegotiation.

Assumption 3 (Strategic Debt Service) If equity holders can make the 'takeit-or-leave-it' offer to debt holders regarding debt service, then there exist two mutually exclusive regions $\mathcal{S}$ and $\mathcal{D}$ such that:

1. Default occurs when the process $(P, V)$ first hits the region $\mathcal{D}$,

2. For all $(p, v) \in \mathcal{S}$, we have $s(p, v)<c$ so that $D(p, v)=X(p, v)$,

3. For all $(p, v) \in \mathcal{C}$, we have $s(p, v)=c$.

We note that there is still a possibility of liquidation even in the presence of debt renegotiation, because equity holders want to liquidate the firm before default if the tangible asset value $V$ is sufficiently high. This is a significant difference in our model from Mella-Barral and Perraudin (1997). Also, from Assumption 3 and Equation (17), the service flow function $s(p, v)$ must be given by

$$
s(p, v)= \begin{cases}c, & \text { for }(p, v) \in \mathcal{C}, \\ \xi p-\eta v, & \text { for }(p, v) \in \mathcal{S}_{1}:=\mathcal{S} \cap\{p / v>\underline{b}\}, \\ \left(r-\mu_{v}\right) v, & \text { for }(p, v) \in \mathcal{S}_{2}:=\mathcal{S} \cap\{p / v \leq \underline{b}\},\end{cases}
$$

in order to ensure the equality $D(p, v)=X(p, v)$, where $\underline{b}$ is given by (18). Note that the renegotiation region $\mathcal{S}$ is divided into two sub-regions $\mathcal{S}_{1}$ and $\mathcal{S}_{2}$.

\subsection{Debt and Equity Values}

As before, we denote the time of default by $\tau_{1}$ and the time of liquidation by $\tau_{2}$. In the presence of debt renegotiation, debt holders will receive coupon payments $s(p, v)$ until either default epoch $\tau_{1}$ or liquidation time $\tau_{2}$, whichever happens first. If equity holders decide to liquidate the firm before default, debt holders receive 
the face value $c / r$ at the liquidation time $\tau_{2}$. If they decide to default, the firm is taken over by debt holders. The strategic debt service is performed while the process $(P, V)$ stays in the region $\mathcal{S}$. Hence, the equity and debt values are given, respectively, by

$$
\begin{aligned}
F(p, v)=\sup _{\tau_{1}, \tau_{2} \in \mathcal{T}} \mathbb{E}\left[\int_{0}^{\tau_{1} \wedge \tau_{2}} \mathrm{e}^{-r t}(P(t)-\eta V(t)\right. & -s(P(t), V(t))) \mathrm{d} t \\
& \left.+\mathbf{1}_{\left\{\tau_{1}>\tau_{2}\right\}} \mathrm{e}^{-r \tau_{2}}\left(V\left(\tau_{2}\right)-\frac{c}{r}\right)\right],
\end{aligned}
$$

and

$$
\begin{aligned}
D(p, v)=\mathbb{E}\left[\int_{0}^{\tau_{1} \wedge \tau_{2}} \mathrm{e}^{-r t} s(P(t), V(t)) \mathrm{d} t\right. & +\mathbf{1}_{\left\{\tau_{1}>\tau_{2}\right\}} \mathrm{e}^{-r \tau_{2}} \frac{c}{r} \\
& \left.+\mathbf{1}_{\left\{\tau_{1} \leq \tau_{2}\right\}} \mathrm{e}^{-r \tau_{1}} X\left(P\left(\tau_{1}\right), V\left(\tau_{1}\right)\right)\right],
\end{aligned}
$$

where $\mathcal{T}$ denotes the set of admissible stopping times in $[0, \infty) \times[0, \infty)$.

It is well known that the equity value $F(p, v)$ satisfies the PDE

$$
\begin{cases}F(p, v)=v-\frac{c}{r}, & \text { for }(p, v) \in \mathcal{L}, \\ \mathcal{A} F(p, v)+p-\eta v-c=0, & \text { for }(p, v) \in \mathcal{C}, \\ \mathcal{A} F(p, v)+(1-\xi) p=0, & \text { for }(p, v) \in \mathcal{S}_{1}, \\ \mathcal{A} F(p, v)+p-\left(\eta+r-\mu_{v}\right) v=0, & \text { for }(p, v) \in \mathcal{S}_{2}, \\ F(p, v)=0, & \text { for }(p, v) \in \mathcal{D},\end{cases}
$$

where the partial differential operator $\mathcal{A}$ is defined in (6). Because the boundaries between the regions are not known in advance, the problem to solve the PDE (22) is a free-boundary problem.

Note again that the second equation in (22) has no closed-form solution due to the constant term $c$. In contrast, the fourth equation has a closed-form solution and the boundary $\mathcal{B}_{D S_{2}}$ between $\mathcal{S}_{2}$ and $\mathcal{D}$ is determined by the corresponding valuematching and smooth-pasting conditions. That is, applying the ordinary arguments, we obtain

$$
F(p, v)=\frac{p}{r-\mu_{p}}-\frac{\left(\eta+r-\mu_{v}\right) v}{r-\mu_{v}}+\frac{\left(r-\mu_{v}+\eta\right) v}{(1-\lambda)\left(r-\mu_{v}\right)}\left(\frac{p}{b v}\right)^{\lambda}, \quad \text { for }(p, v) \in \mathcal{S}_{2}
$$

where $\lambda$ is given in Proposition 1 and the default threshold is

$$
b=\frac{\lambda}{\lambda-1} \frac{r-\mu_{p}}{r-\mu_{v}}\left(r-\mu_{v}+\eta\right)
$$

which is the same as in (6), whence we obtain $b=b^{*}$. This means that the default epoch is pushed back to the liquidation time of the pure equity firm in the presence of debt renegotiation. This is so, because debt holders accept the take-it-or-leaveit offer until they do not want to take over the firm. Hence, the boundary $\mathcal{B}_{D S_{2}}$ between $\mathcal{S}_{2}$ and $\mathcal{D}$ is given by the straight line $p / v=b^{*}$. As soon as the process 
$(P, V)$ hits this boundary, debt holders stop the renegotiation and liquidate the firm immediately.

Similarly, the third equation in (22) has a closed form solution and the boundary $\mathcal{B}_{S_{1} S_{2}}$ between $\mathcal{S}_{1}$ and $\mathcal{S}_{2}$ is already known as in (21). ${ }^{15}$ Hence, we obtain

$$
F(p, v)=\frac{(1-\xi) p}{r-\mu_{p}}+\frac{\left(1-\xi^{\lambda}\right)\left(r-\mu_{v}+\eta\right) v}{\xi^{\lambda}(1-\lambda)\left(r-\mu_{v}\right)}\left(\frac{p}{\underline{b} v}\right)^{\lambda}, \quad \text { for }(p, v) \in \mathcal{S}_{1}
$$

where $\underline{b}$ is given by (18).

The boundary $\mathcal{B}_{C L}\left(\mathcal{B}_{C D}\right.$, respectively) between $\mathcal{L}(\mathcal{D})$ and $\mathcal{C}$ should be obtained as a part of the free-boundary problem for the first (fifth) and second equations in (22). It remains to determine the boundary $\mathcal{B}_{C S}$ between $\mathcal{S}=\mathcal{S}_{1} \cup \mathcal{S}_{2}$ and $\mathcal{C}$. This boundary is selected by equity holders so as to minimize the debt value $D(p, v)$, where $D(p, v)$ is equal to $X(p, v)$ in the region $\mathcal{S}{ }^{16}$ Moreover, from the fact that $W(p, v)=F(p, v)+D(p, v)$ and the firm value $W(p, v)$ is irrelevant to the existence of debt renegotiation (see Equation (24)), minimization of $D(p, v)$ is equivalent to maximization of $F(p, v)$. Therefore, the boundary $\mathcal{B}_{C S_{1}}\left(\mathcal{B}_{C S_{2}}\right.$, respectively) is obtained as a part of the free-boundary problem for the second and third (fourth) equations in (22).

Next, the debt value $D(p, v)$ satisfies the following PDE:

$$
\begin{cases}D(p, v)=\frac{c}{r}, & \text { for }(p, v) \in \mathcal{L}, \\ \mathcal{A} D(p, v)+c=0, & \text { for }(p, v) \in \mathcal{C}, \\ D(p, v)=X(p, v), & \text { for }(p, v) \in \mathcal{S}, \\ D(p, v)=v, & \text { for }(p, v) \in \mathcal{D} .\end{cases}
$$

Given the boundaries that have been obtained by solving the free-boundary problem (22), the second equation must satisfy the value-matching condition to the other equations on the boundaries.

Finally, the firm value is defined by $W(p, v)=F(p, v)+D(p, v)$, so that it satisfies the following PDE:

$$
\begin{cases}W(p, v)=v, & \text { for }(p, v) \in \mathcal{L} \\ \mathcal{A} W(p, v)+p-\eta v=0, & \text { for }(p, v) \in(\mathcal{L} \cup \mathcal{D})^{c} \\ W(p, v)=v, & \text { for }(p, v) \in \mathcal{D}\end{cases}
$$

Here, the second equation must satisfy the value-matching condition to the other equations on the boundaries.

As before, we solve the PDEs (22) and (23) numerically by using a finite difference method. For this purpose, it is helpful to derive the value functions in closed form for $v, p \rightarrow 0$ and for sufficiently large $p$ and/or $v$. Note that, because strategic debt service is never performed for sufficiently large $p$ and/or $v$, the value functions there are the same as those without renegotiation.

\footnotetext{
${ }^{15}$ Of course, the boundary $\mathcal{B}_{S_{1} S_{2}}$ (straight line $p / v=\underline{b}$ ) is derived by solving the corresponding value-matching and smooth-pasting conditions of the third and fourth equations in (22).

${ }^{16}$ Mella-Barral and Perraudin (1997) derive the boundary $\mathcal{B}_{C S}$ by using no-arbitrage arguments. However, it can be readily verified that the no-arbitrage condition is equivalent to minimizing the debt value.
} 


\subsubsection{The case that $v \rightarrow 0$}

Suppose that the value function $F(p, v)$ is sufficiently smooth. Then, from (21), there is some threshold $K$ so that the service flow function is given by

$$
s(p, 0+)= \begin{cases}c, & \text { for } p>K, \\ \xi p, & \text { for } p \leq K .\end{cases}
$$

Also, from (22), the value function $F(p, 0+)$ satisfies the following ODE for some default threshold $\tilde{K}$ :

$$
\begin{cases}\frac{1}{2} \sigma_{p}^{2} p^{2} F_{p p}(p, 0+)+\mu_{p} p F_{p}(p, 0+)-r F(p, 0+)+p-c=0, & \text { for } p>K, \\ \frac{1}{2} \sigma_{p}^{2} p^{2} F_{p p}(p, 0+)+\mu_{p} p F_{p}(p, 0+)-r F(p, 0+)+(1-\xi) p=0, & \text { for } \tilde{K}<p \leq K, \\ F(p, 0+)=0, & \text { for } p \leq \tilde{K},\end{cases}
$$

because liquidation never occurs from Proposition 2. Looking at the second and third equations, we find that $\tilde{K}$ does not exist and default never occurs either. Since the threshold $K$ is selected by equity holders so as to maximize the equity value $F(p, 0+)$, this is a free-boundary problem.

Using the ordinary arguments, we then have the following.

Proposition 6 The equity value $F(p, 0+)$ is obtained as

$$
F(p, 0+)= \begin{cases}\frac{p}{r-\mu_{p}}-\frac{c}{r}+\frac{1}{1-\beta} \frac{c}{r}\left(\frac{p}{K}\right)^{\beta}, & \text { for } p>K \\ \frac{(1-\xi) p}{r-\mu_{p}}, & \text { for } p \leq K\end{cases}
$$

where $\beta$ is given as in Proposition 2 and the threshold is obtained as

$$
K=\frac{\beta}{\beta-1} \frac{r-\mu_{p}}{\xi} \frac{c}{r} .
$$

Note that, since equity holders never default the firm and $K>\hat{K}$, renegotiation occurs earlier than the default without renegotiation.

The debt value is obtained by the value-matching condition on the given threshold $K$ as

$$
D(p, 0+)= \begin{cases}\frac{c}{r}-\frac{1}{1-\beta} \frac{c}{r}\left(\frac{p}{K}\right)^{\beta}, & \text { for } p>K \\ \frac{\xi p}{r-\mu_{p}}, & \text { for } p \leq K\end{cases}
$$

Of course, the firm value is given by

$$
W(p, 0+)=F(p, 0+)+D(p, 0+)=\frac{p}{r-\mu_{p}},
$$

which coincides with the pure equity case. 


\subsubsection{The case that $p \rightarrow 0$}

When $p \rightarrow 0$, we know that there are thresholds $U$ and $L$ so that $F(0+, v)=v-\frac{c}{r}$ for $v \geq U$ and $F(0+, v)=0$ for $v \leq L$. That is, equity holders liquidate the tangible assets when $v \geq U$, while they choose default when $v \leq L$. For $L<v<U$, suppose that renegotiation is applicable. Then, from Equation (22), the service flow function should be given by

$$
s(0+, v)= \begin{cases}c, & \text { for } v>M, \\ \left(r-\mu_{v}\right) v, & \text { for } v \leq M,\end{cases}
$$

for some $M \in(L, U)$. However, when $p \rightarrow 0$, the state $(0+, v)$ for $0<v \leq M$ automatically satisfies the condition $p / v \leq b^{*}$, so that debt holders choose default rather than renegotiation. This means that renegotiation is not applicable when $p \rightarrow 0$. These results are summarized in the next proposition.

Proposition 7 When $p \rightarrow 0$, strategic debt service is not applicable, and the equity value is the same as that given in Proposition 3. Of course, the debt and firm values are unchanged and given by Propositions 4 and 5, respectively.

\subsection{Numerical Analyses}

In this section, we provide numerical examples to explain how strategic debt service is performed. Figure 10 depicts the calculation results for the base case with parameters listed in Table 1, where the four regions (operating $\mathcal{C}$, debt renegotiation $\mathcal{S}$, default $\mathcal{D}$ and liquidation $\mathcal{L}$ ) are obtained by solving the free-boundary problem (22). ${ }^{17}$ As before, we employ the finite difference method with successive overrelaxations in terms of the transformed variables $(x, y)$ defined by Equation (C.3), which are then converted back to the values of $(p, v)$. Note the difference between Figures 1 and 10. In Figure 10, the default region without renegotiation surrounded by a curve in the bottom-left corner is divided into three parts: default region $\mathcal{D}$ above the line $p / v=b^{*}$, renegotiation region $\mathcal{S}_{1}$ with service flow $\xi p-\eta v$ below the line $p / v=\underline{b}$, renegotiation region $\mathcal{S}_{2}$ with service flow $\left(r-\mu_{v}\right) v$ between $\mathcal{D}$ and $\mathcal{S}_{1}$. The other regions look similar, although they are not the same as before because of the possibility of debt renegotiation.

[Figure 10 is inserted around here.]

As in Figure 1, the dashed and chained lines in Figure 10 represent the straight lines $p / v=b^{*}$ and $p / v=\underline{b}$, respectively. The points $c / r=1.3333, \hat{U}=1.4693$ and $\hat{L}=1.2220$ on the $v$-axis and the point $K=0.01996$ on the $p$-axis are also appended there.

As before, in Figure 10, we add typical sample paths of the process $(P, V)$ in order to explain the renegotiation/default/liquidation mechanism in our model. For example, starting from a point $(p, v)$ in the operating region $\mathcal{C}$;

\footnotetext{
${ }^{17}$ These regions are recognized based on the results in Propositions 6 and 7 .
} 
1. The process $(P, V)$ hits the region $\mathcal{S}_{1}$ before default and liquidation. In this case (sample path (a)), equity holders offer the service flow $\xi p-\eta v$ and debt holders accept it. The firm is operated by equity holders. After that, the service flow may change to $\left(r-\mu_{v}\right) v$ when the process $(P, V)$ hits the line $p / v=\underline{b}$. Moreover, the firm may be liquidated by debt holders if the process $(P, V)$ hits the line $p / v=b^{*}$. If the process $(P, V)$ returns to the region $\mathcal{C}$, the service flow goes back to the contractual coupon $c$ and the debt renegotiation is reset.

2. The process $(P, V)$ first crosses the line $p / v=\underline{b}$ and then hits the region $\mathcal{S}_{2}$. In this case (sample path (b)), equity holders offer the service flow $\left(r-\mu_{v}\right) v$ and debt holders accept it. After that, the firm may be liquidated if the process $(P, V)$ hits the line $p / v=b^{*}$. If the process $(P, V)$ returns to the region $\mathcal{C}$, the service flow goes back to $c$ and the debt renegotiation is reset.

3. The process $(P, V)$ first crosses the line $p / v=b^{*}$ and then hits the liquidation region $\mathcal{L}$ without visiting the default region $\mathcal{D}$. In this case (sample path $(\mathrm{c})$ ), equity holders liquidate tangible assets and repay the face value of debt to debt holders. Since liquidation occurs above the line $p / v=b^{*}$, it is a late liquidation.

4. The process $(P, V)$ first crosses the line $p / v=b^{*}$ and then hits the default region $\mathcal{D}$ without visiting the liquidation region $\mathcal{L}$. In this case (sample path (d)), equity holders default and debt holders liquidate the firm immediately. Since liquidation occurs above the line $p / v=b^{*}$, it is a late liquidation.

\subsubsection{Significance of tangible assets}

First, our model admits a late liquidation, because there is an operating region beyond the line $p / v=b^{*}$ between default region $\mathcal{D}$ and liquidation region $\mathcal{L}$. Recall that this gap shrinks and diminishes as the volatility $\sigma_{v}$ of tangible assets tends to zero.

The gap between default and liquidation regions can also produce the possibility of liquidity default. As Hart and Moore $(1994,1998)$ emphasize, it is important to distinguish liquidity default from strategic default. While strategic default occurs when the firm fails to pay full amount of debt service in debt contract even though it possesses the resource to do so, liquidity default occurs when the firm's cash flows are insufficient to cover the debt service. In our model, default following sample path (d) in Figure 10 corresponds to liquidity default, because default occurs when the value of tangible assets is relatively high and the EBIT is substantially low. In this case, the firm must pay a high maintenance cost for the tangible assets despite of the low earnings, so that equity holders cannot afford to carry out the debt contract, resulting in liquidity default. Our model can treat strategic and liquidity defaults within the same framework.

Note that one-factor models can produce only strategic default, but not liquidity default (see Figure 2). Also, as sample path (c) ((d), respectively) suggests, equity holders may default (liquidate) the firm without offering the strategic debt service 
in our model. This behavior does not appear in the framework of Mella-Barral and Perraudin (1997).

\subsubsection{Contribution of strategic debt service to credit spreads}

Using numerical examples, we investigate how much strategic debt service contributes to credit spreads. Recently, Davydenko and Strebulaev (2007) showed that (i) the corporate bond prices are affected by the possibility of renegotiation, especially when the costs of liquidation are likely to be high, and (ii) changes in corporate bond price due to renegotiation are high, especially when the credit quality of the issuer is relatively row. In our model, (i) high cost of liquidation means a low value of tangible assets, and (ii) low credit quality means a small value of tangible assets or small value of EBIT. The additional credit spreads shown in Figure 11 support these empirical findings.

In Figure 11, the contour lines show the additional credit spreads (bp), defined by

$$
\frac{c}{D(p, v)}-\frac{c}{\hat{D}(p, v)}
$$

due to the debt renegotiation. The bold dashed and solid lines plot the optimal default and liquidation boundaries without renegotiation, respectively, while the white and black circles plot the optimal liquidation and renegotiation boundaries with renegotiation, respectively. The parameters are taken from Table 1. It is explicitly observed that the additional credit spreads are high when the value of tangible assets is low and the value of EBIT is small. Note that, in Mella-Barral and Perraudin (1997), additional credit spreads do not depend on the value of EBIT.

[Figure 11 is inserted around here.]

Davydenko and Strebulaev (2007) also showed that quantitative contribution of strategic debt service to credit spreads is below transaction costs, assuming that creditors have no bargaining power in their pricing model. This result contradicts the results shown by the theoretical models of debt renegotiation, including Mella-Barral and Perraudin (1997), Fan and Sundaresan (2000), and Anderson and Sundaresan (1996). These theoretical models suggest that, when creditors have little bargaining power, a large part of credit spreads may be due to the possibility of renegotiation of debt service. Hence, based on the theoretical results, Davydenko and Strebulaev (2007) conclude that bondholders are likely to have significant bargaining power. However, our model suggests that, even though equity holders have full bargaining power, the additional credit spreads due to debt renegotiation are significantly low compared to the existing theoretical results, as is shown in Figure 11. This is because our model considers the possibility of liquidity default, which allows no opportunity of renegotiation for equity holders, despite that they have full bargaining power.

Through ample numerical experiments, we find that changes in credit spreads due to renegotiation are likely to be affected in large parts by the parameter $\xi$ as shown in Figures 12. Also, the difference in optimal liquidation boundaries for the models with and without renegotiation is quite low when the correlation $\rho$ between tangible asset value and EBIT is positive. In reality, efficiency loss of EBIT is likely 
to be small (i.e., $\xi$ is close to unity) if creditors have enough knowledge about the firm. Also, the asset value and the profit flow are positively correlated (i.e., $\rho$ is positive and away from zero). Hence, we conclude that, even when creditors have little bargaining power, the actual contribution of strategic debt service to credit spreads is relatively small, which agrees with the empirical findings reported in Davydenko and Strebulaev (2007).

[Figure 12 is inserted around here.]

\subsubsection{Sensitivity analysis of optimal boundaries}

In this section, we perform comparative statics analyses of optimal boundaries with respect to the model parameters. Again, we use the base parameters listed in Table 1 . Both the optimal default boundary $\hat{\mathcal{B}}_{C D}$ and liquidation boundary $\hat{\mathcal{B}}_{C L}$ without renegotiation are appended to all the figures for the sake of comparison. Note that, in all the cases, the optimal liquidation boundaries $\mathcal{B}_{C L}$ and $\hat{\mathcal{B}}_{C L}$ with and without renegotiation, respectively, are very similarly. Of course, the optimal renegotiation boundary $\mathcal{B}_{C S}$ looks very different from the optimal default boundary $\hat{\mathcal{B}}_{C D}$ due to the possibility of renegotiation.

Figure 13 shows the optimal renegotiation boundary $\mathcal{B}_{C S}$ and liquidation boundary $\mathcal{B}_{C L}$ for $\sigma_{v}=0.075,0.15,0.25$, the volatility of tangible assets. As volatility $\sigma_{v}$ increases, the liquidation boundaries for the both cases move upward for relatively small EBIT values, ${ }^{18}$ which gives equity holders a higher value of option to liquidate. As a result, the optimal default boundary $\hat{\mathcal{B}}_{C D}$ and renegotiation boundary $\mathcal{B}_{C S}$ move downward for higher volatility. In other words, for lower volatility, equity holders decide more likely to default the firm earlier, because lower volatility pushes the liquidation boundary downward and equity holders possess a smaller value of option to liquidate.

[Figure 13 is inserted around here.]

Figure 14 illustrates the sensitivity of the optimal boundaries with respect to the efficiency loss parameter $\xi$. It is observed that the optimal renegotiation boundary $\mathcal{B}_{C S}$ is quite sensitive to the value, which is consistent with earlier works. ${ }^{19}$ On the other hand, the liquidation boundary $\mathcal{B}_{C L}$ is not affected by $\xi$, as expected.

[Figure 14 is inserted around here.]

Figure 15 shows the sensitivity of the optimal boundaries with respect to the correlation $\rho$. Note that, while the boundary $\mathcal{B}_{C L}$ to liquidate the firm is very sensitive to the correlation, ${ }^{20}$ the impact of correlation on the boundary $\mathcal{B}_{C S}$ to

\footnotetext{
${ }^{18}$ Note that the optimal liquidation boundary $b$ for pure equity firm is not linear with respect to $\sigma_{v}$. Hence, the optimal liquidation boundaries cross each other as shown in Figure 13.

${ }^{19}$ Davydenko and Strebulaev (2007) show that the possibility of debt renegotiation is affected by the cost of liquidation. Because they do not distinguish liquidation from default, their empirical results apply for default cost.

${ }^{20}$ Note that the optimal liquidation boundary $b$ for pure equity firm has a different slope for different correlation $\rho$.
} 
enter renegotiation is very limited. This is important for practical use because the correlation $\rho$ is usually hard to estimate.

[Figure 15 is inserted around here.]

Finally, we find that the volatility of EBIT, $\sigma_{p}$, also has a significant impact on the optimal boundary $\mathcal{B}_{C S}$. That is, higher volatility rises the values of option to default and option to renegotiate. These results are explicitly observed in Figure 16.

[Figure 16 is inserted around here.]

Summarizing, the optimal renegotiation boundary $\mathcal{B}_{C S}$ is sensitive to default costs and the business volatility, while it is not sensitive to the correlation between business assets and collaterals. The same results are applied to the optimal default boundary $\hat{\mathcal{B}}_{C D}$ without renegotiation. On the other hand, the optimal liquidation boundary $\mathcal{B}_{C L}$ is not sensitive to default costs, while it is sensitive to the business volatility and the correlation. The liquidation boundary is not affected by the introduction of debt renegotiation.

\subsubsection{Agency problems with renegotiation}

For a levered firm, if the firm is on the brink of default, the equity value becomes very low and equity holders have an incentive to raise the business volatility to increase the expected payoff, because the equity is a call option written on the firm value. In the case of no renegotiation, we observed through numerical experiments that debt holders also have the same incentive at the brink of default in order to move far away from default boundary. In this section, we perform the same numerical experiments as before.

First, Figure 17 illustrates the impact of $\sigma_{p}$ on the percentage change of equity value, i.e.,

$$
\frac{F\left(p, v \mid \sigma_{p}=0.4\right)-F\left(p, v \mid \sigma_{p}=0.3\right)}{F\left(p, v \mid \sigma_{p}=0.3\right)},
$$

which shows the equity holders' incentive to raise the business risk $\sigma_{p}$. As expected, equity holders have a strong incentive to raise the business risk, especially when default becomes almost certain. Recall that the default boundary is changed to the default boundary of a pure equity firm (the solid line) due to the introduction of renegotiation. Compared with the incentive for the case of no renegotiation (see Figure 6), we can say that debt renegotiation decreases the possibility of risk shifting.

[Figure 17 is inserted around here.]

On the other hand, Figure 18 shows the impact of risk shifting by equity holders on the debt value. The contour line plots the percentage change of debt value, i.e.,

$$
\frac{D\left(p, v \mid \sigma_{p}=0.4\right)-D\left(p, v \mid \sigma_{p}=0.3\right)}{D\left(p, v \mid \sigma_{p}=0.3\right)},
$$

which shows the debt holders' incentive to raise the business risk $\sigma_{p}$. When the value of EBIT is very high, debt holders have no incentive to raise the business risk as for 
the case of no renegotiation (see Figure 7). However, debt holders have an incentive to raise the business risk in the region of renegotiation. ${ }^{21}$ This is so, because debt holders are forced to act as if they had an option to liquidate the firm and then suffered from the reduced service flow (21) in the region $\mathcal{S}=\mathcal{S}_{1} \cup \mathcal{S}_{2}$. From (23), the debt value in $\mathcal{S}$ is equal to $X(p, v)$, which is strictly convex in $(p, v)$. Hence, debt holders wish to move away from the region of renegotiation to the operating region $\mathcal{C}$.

[Figure 18 is inserted around here.]

Note also that the debt holders' incentive to raise the business risk does not appear on the brink of default (the solid line; the default boundary for a pure equity firm), unlike the case of no renegotiation (see Figure 7). The reason for this is that debt holders wish to liquidate the firm at the boundary $p / v=\underline{b}$, which comes earlier than the liquidation boundary $p / v=b^{*}$ of a pure equity firm. When the eventual default cannot be avoided after renegotiation with equity holders, debt holders have no incentive to manage the firm's risk any longer!

\section{Some Discussions}

In this section, we discuss two important topics using our model. The first one is the case that debt holders have full bargaining power, and the other is the case of departures from absolute priority rule (APR).

\subsection{Debt Holder Offers}

Suppose that debt holders have full bargaining power about coupon payments. Since equity holders receive nothing if they default the firm, debt holders can exploit all the firm value by renegotiation. See Mella-Barral and Perraudin (1997) for details.

We define the service flow function $q(s, v)$ and the region $\mathcal{Q}$ in which debt holders enter renegotiation as follows. First, the service flow that debt holders offer is given by

$$
q(p, v)= \begin{cases}c, & \text { for }(p, v) \in \mathcal{C}, \\ p-\eta v, & \text { for }(p, v) \in \mathcal{Q},\end{cases}
$$

and the profit flow that equity holders accept is given by

$$
f(p, v)= \begin{cases}p-\eta v-c, & \text { for }(p, v) \in \mathcal{C}, \\ 0, & \text { for }(p, v) \in \mathcal{Q} .\end{cases}
$$

When debt holders carry out strategic debt service, equity holders must suffer from the same situation as default.

On the other hand, the profit flow for debt holders is given by

$$
d(p, v)= \begin{cases}c, & \text { for }(p, v) \in \mathcal{C}, \\ p-\eta v, & \text { for }(p, v) \in \mathcal{Q},\end{cases}
$$

\footnotetext{
${ }^{21}$ Note that there exists some region in which the debt holders' incentive to raise the business risk is higher than that of equity holders.
} 
so that debt holders enjoy the same situation as if they owned the firm without any loss by debt renegotiation.

Next, note that the region $\mathcal{Q}$ coincides with the region $\hat{\mathcal{D}} \cap\left\{p / v>b^{*}\right\}$ and only difference between the model with debt holders' offer and the model without renegotiation appears in the debt value $D(p, v)$. Namely, while the equity value in this case is $F(p, v)=\hat{F}(p, v)$, the debt value is given by

$$
\begin{cases}D(p, v)=\frac{c}{r}, & \text { for }(p, v) \in \mathcal{L}=\hat{\mathcal{L}}, \\ \mathcal{A} D(p, v)+c=0, & \text { for }(p, v) \in \mathcal{C}=\hat{\mathcal{C}}, \\ \mathcal{A} D(p, v)+p-\eta v=0, & \text { for }(p, v) \in \mathcal{Q}=\hat{\mathcal{D}} \cap\left\{p / v>b^{*}\right\}, \\ D(p, v)=v, & \text { for }(p, v) \in \mathcal{D}=\hat{\mathcal{D}} \cap\left\{p / v \leq b^{*}\right\} .\end{cases}
$$

We explain how default and liquidation occur when debt holders have full bargaining power using Figure 19. As shown in (25), we can use the same calculation results as in Figure 1. The parameters are taken from Table 1. Note the difference between Figures 1 and 19. In Figure 19, the default region in Figure 1 surrounded by a curve in the bottom-left corner is divided into two parts: default region $\mathcal{D}$ above the line $p / v=b^{*}$ and renegotiation region $\mathcal{Q}$ below the line $p / v=b^{*}$. In Figure 19, the dashed line represents the straight line $p / v=b^{*}$ as in Figure 1 . We also add the points $c / r=1.3333, \hat{U}=1.4693$ and $\hat{L}=1.2220$ on the $v$-axis, and the point $\hat{K}=0.01397$ on the $p$-axis in this example.

[Figure 19 is inserted around here.]

In Figure 19, we add typical sample paths of the process $(P, V)$ in order to explain the renegotiation/default/liquidation mechanism, when debt holders offer the strategic debt service. Starting from a point $(p, v)$ in the operating region $\mathcal{C}$;

1. The process $(P, V)$ hits the region $\mathcal{Q}$ before default and liquidation. In this case (sample path (a)), debt holders offer the service flow $p-\eta v$ and equity holders accept it. The firm is operated by equity holders. After that, the firm may be liquidated if the process $(P, V)$ touches the line $p / v=b^{*}$. If the process $(P, V)$ returns the region $\mathcal{C}$, the service flow goes back to the contractual coupon $c$ and the debt renegotiation is reset.

2. The process $(P, V)$ first crosses the line $p / v=b^{*}$ and then hits the default region $\mathcal{D}$ without visiting the liquidation region $\mathcal{L}$. In this case (sample path (b)), equity holders default and debt holders liquidate the firm immediately. Since liquidation occurs above the line $p / v=b^{*}$, it is a late liquidation.

3. The process $(P, V)$ first crosses the line $p / v=b^{*}$ and then hits the liquidation region $\mathcal{L}$ without visiting the default region $\mathcal{D}$. In this case (sample path $(\mathrm{c})$ ), equity holders liquidate tangible assets and repay the face value of debt to debt holders. Since liquidation occurs above the line $p / v=b^{*}$, it is a late liquidation.

Note that, in the case of sample paths (b) and (c), there is no debt renegotiation. 


\subsection{Departures from Absolute Priority Rule}

Now, we consider departures from absolute priority rule (APR) as in Mella-Barral (1999). In Mella-Barral (1999), liquidation planned by equity holders can be earlier or later than that of the corresponding pure equity firm, depending on the model parameters. In the case of early liquidation, renegotiation can make the liquidation (decided by equity holders) occur at the same timing as that of the pure equity firm. In the case of late liquidation, this role is taken by departures from APR. See Mella-Barral (1999) for details.

Recall that, unlike Mella-Barral (1999), liquidation planned by equity holders can be earlier or later than that of the corresponding pure equity firm, even when the process $(P, V)$ starts from the same initial value in our model (see Figure 10). Also, as sample paths (a) and (b) in Figure 10 reveal, renegotiation can make the liquidation of the levered firm (decided by equity holders) occur at the same timing as that of the pure equity firm. However, renegotiation cannot eliminate late liquidation as shown by sample paths (c) and (d). In order to avoid late liquidation, we need to consider departures from APR in our setting too.

Late liquidation occurs after the process $(P, V)$ crosses the line $p / v=b^{*} \cap(p, v) \in$ $\mathcal{C}$ (see, e.g., sample paths (c) and (d) in Figure 10). This suggests us to define the stopping time

$$
\check{\tau}_{0}=\inf \left\{t>0: p / v \leq b^{*} \text { and }(p, v) \in \mathcal{C}\right\},
$$

which denotes the time to departure from APR, since the levered firm is liquidated later than the corresponding pure equity firm if nothing is done at $\check{\tau}_{0}$. Suppose that equity holders have full bargaining power. Then, there is nothing for debt holders but to accept the value of late liquidation. Late liquidation has two possibilities: liquidation by equity holders (sample path (c) in Figure 10) or liquidation by debt holders just after default by equity holders (sample path (d) in Figure 10).

The expected value received by debt holders at time $\check{\tau}_{0}$ is given by

$$
\Delta=\mathbb{E}\left[\mathbf{1}_{\left\{\tau_{1} \leq \tau_{2}\right\}} \mathrm{e}^{-r\left(\tau_{1}-\check{\tau}_{0}\right)} V\left(\tau_{1}\right)+\mathbf{1}_{\left\{\tau_{1}>\tau_{2}\right\}} \mathrm{e}^{-r\left(\tau_{2}-\check{\tau}_{0}\right)} \frac{c}{r}\right],
$$

where, as before, $\tau_{1}$ and $\tau_{2}$ are the default and liquidation times selected by equity holders, respectively. If the firm is liquidated by equity holders at time $\check{\tau}_{0}$, debt holders receive only $\Delta$ and equity holders the residual. Therefore, the equity and debt values in the case of departures from APR are obtained, respectively, as

$$
\begin{aligned}
& \check{F}(p, v)=\sup _{\tau_{1}, \tau_{2} \in \mathcal{T}} \mathbb{E}\left[\int_{0}^{\check{\tau}_{0} \wedge \tau_{1}} \mathrm{e}^{-r t}(P(t)-\eta V(t)\right.-s(P(t), V(t))) \mathrm{d} t \\
&\left.+\mathbf{1}_{\left\{\check{\tau}_{0} \leq \tau_{1}\right\}} \mathrm{e}^{-r \check{\tau}_{0}}\left(V\left(\check{\tau}_{0}\right)-\Delta\right)\right], \\
& \check{D}(p, v)=\mathbb{E}\left[\int_{0}^{\check{\tau}_{0} \wedge \tau_{1}} \mathrm{e}^{-r t} s(P(t), V(t)) \mathrm{d} t+\mathbf{1}_{\left\{\check{\tau}_{0}>\tau_{1}\right\}} \mathrm{e}^{-r \tau_{1}} V\left(\tau_{1}\right)+\mathbf{1}_{\left\{\check{\tau}_{0} \leq \tau_{1}\right\}} \mathrm{e}^{-r \check{\tau}_{0}} \Delta\right] .
\end{aligned}
$$

The total firm value is therefore given by

$$
\begin{aligned}
\check{W}(p, v) & =\check{F}(p, v)+\check{D}(p, v) \\
& =\mathbb{E}\left[\int_{0}^{\check{\tau}_{0} \wedge \tau_{1}} \mathrm{e}^{-r t}(P(t)-\eta V(t)) \mathrm{d} t+\mathbf{1}_{\left\{\check{\tau}_{0}>\tau_{1}\right\}} \mathrm{e}^{-r \tau_{1}} V\left(\tau_{1}\right)+\mathbf{1}_{\left\{\check{\tau}_{0} \leq \tau_{1}\right\}} \mathrm{e}^{-r \check{\tau}_{0}} V\left(\check{\tau}_{0}\right)\right] .
\end{aligned}
$$


Since $\mathcal{D} \subset\left\{p / v \leq b^{*}\right\}$, we obtain $\check{\tau}_{0} \wedge \tau_{1}=\tau_{0}$ from (26), whence we have $\check{W}(p, v)=$ $W^{*}(p, v)$.

\section{Conclusion}

In this paper, we propose a new pricing model for corporate securities issued by a levered firm with the possibility of debt renegotiation. We take the structural approach that the firm's earnings follow a geometric Brownian motion with stochastic collaterals. As in Leland (1994), equity holders can default the firm for their own benefits, when the earnings become insufficient to go on the firm. In addition, equity holders may want to liquidate the firm by repaying the face value of debt to debt holders to get enough residuals, when the value of collaterals becomes sufficiently high. Unlike the existing theoretical models, the bivariate structure can not only capture realistic credit spreads observed in the market, but also explain many empirical findings reported in the literature.

Structural pricing models with debt renegotiation have been studied, among others, by Anderson and Sundaresan (1996), Mella-Barral and Perraudin (1997), MellaBarral (1999) and Fan and Sundaresan (2000), and suggest that a large part of credit spreads may be due to the possibility of strategic default risk, when creditors have little bargaining power. Debt renegotiation by strategic debt service successfully provides realistic credit spreads observed in the market. However, recent empirical studies such as Acharya et al. (2006) and Davydenko and Strebulaev (2007) point out that the contribution of strategic debt service to credit spreads suggested by the theoretical models is too large. Also, Davydenko and Strebulaev (2007) find the fact that the bond prices are likely to be affected by the possibility of renegotiation, especially when the costs of liquidation are likely to be high and credit quality of the issuer is relatively low. Our model can explain these empirical findings.

Our model is an extension of the existing models to the bivariate framework by introducing the value of tangible assets, which plays the role of collaterals. Because of the bivariate feature, we can distinguish strategic default, liquidity default and the ordinary liquidation. It is shown that, in our model, liquidity default can occur when the value of collaterals is relatively high but the value of EBIT is substantially low, irrespective of the bargaining power of equity holders. When the value of tangible assets is sufficiently high and the EBIT is low, our model selects liquidation. Otherwise, the firm terminates as strategic default; however, the patterns depend on the sample path of the bivariate process, not the initial parameter values. This means that equity holders can select either liquidity default or liquidation, depending on the economical condition, without entering debt renegotiation. This is a significant difference between our model and the other existing models in the debt renegotiation literature.

The possibility of liquidity default and liquidation without entering debt renegotiation is quite important from the pricing perspectives. If renegotiation always occurs in a given model, the effect of strategic debt service will be overstated and its contribution to credit spreads evaluated from the model becomes too high, which explains the empirical result reported in Davydenko and Strebulaev (2007). In fact, our model can produce credit spreads consistent with the empirical findings even 
when equity holders have full bargaining power, as expected.

As future studies, it seems important to consider the optimal capital structure of a firm in the bivariate setting. To this end, we need to develop an efficient numerical method to solve the associated bivariate free-boundary problems, as mentioned in Remark 1. Furthermore, we want to relax Assumption 2 to be more realistic. That is, consider the situation that raiders choose the acquisition timing so as to maximize their return under imperfect competitive market. It seems interesting to investigate how equity holders' strategy changes according to the change of liquidation time.

\section{A Proofs}

\section{A.1 Proof of Proposition 1}

Because the value function $W^{*}(p, v)$ is first-order homogeneous, we can define a new function

$$
\bar{W}(z)=\frac{1}{v} W^{*}(p, v)=W^{*}(z, 1)
$$

or, equivalently,

$$
v \bar{W}(z)=W^{*}(p, v),
$$

by the change-of-variable $z=p / v$. All the partial derivatives for $W^{*}(p, v)$ can be written in terms of the derivatives of $\bar{W}(z)$ as

$$
\begin{gathered}
W_{p}^{*}(p, v)=\bar{W}^{\prime}(z), \quad W_{p p}^{*}(p, v)=\frac{1}{v} \bar{W}^{\prime \prime}(z), \quad W_{p v}^{*}(p, v)=-\frac{p}{v^{2}} \bar{W}^{\prime \prime}(z), \\
W_{v}^{*}(p, v)=\bar{W}(z)-\frac{p}{v} \bar{W}^{\prime}(z), \quad W_{v v}^{*}(p, v)=\frac{p^{2}}{v^{3}} \bar{W}^{\prime \prime}(z) .
\end{gathered}
$$

Substituting these derivatives into the PDE (3), we obtain the ordinary differential equation (ODE)

$$
\frac{1}{2} \sigma_{z}^{2} z^{2} \bar{W}^{\prime \prime}(z)+\left(\mu_{p}-\mu_{v}\right) z \bar{W}^{\prime}(z)-\left(r-\mu_{v}\right) \bar{W}(z)+z-\eta=0,
$$

where $\sigma_{z}^{2}=\sigma_{p}^{2}+\sigma_{v}^{2}-2 \rho \sigma_{p} \sigma_{v}$. Following the standard arguments, the ODE can be solved as

$$
\bar{W}(z)= \begin{cases}\frac{z}{r-\mu_{p}}-\frac{\eta}{r-\mu_{v}}+\frac{\left(r-\mu_{v}+\eta\right)}{(1-\lambda)\left(r-\mu_{v}\right)}\left(\frac{z}{b^{*}}\right)^{\lambda}, & \text { for } z>b^{*} \\ 1, & \text { for } z \leq b^{*}\end{cases}
$$

where $\lambda$ and $b^{*}$ are given as in Proposition 1. The value function (5) can be derived from (A.1) at once.

\section{A.2 Proof of Proposition 3}

It is well known that the ODE (13) has a general solution of the form

$$
\hat{F}(0+, v)=A_{1} v^{\gamma_{1}}+A_{2} v^{\gamma_{2}}-\frac{\eta v}{r-\mu_{v}}-\frac{c}{r},
$$


where $\gamma_{1}<0$ and $\gamma_{2}>1$ are the roots of the characteristic equation given in Proposition 3. The coefficients $A_{1}, A_{2}$ and the upper and lower thresholds $\hat{U}, \hat{L}$ are determined by the value-matching and smooth-pasting conditions.

If the value $v$ of tangible assets becomes sufficiently large, equity holders prefer to liquidate the firm and receive the residual value $v-c / r$. Therefore, for some upper threshold $\hat{U}$, the following value-matching and smooth-pasting conditions hold:

$$
\hat{F}(0+, \hat{U})=\hat{U}-\frac{c}{r}, \quad \hat{F}^{\prime}(0+, \hat{U})=1 .
$$

On the other hand, if the residual value becomes worthless, then they prefer to default the firm. Hence, for some lower threshold $\hat{L}$, we have

$$
\hat{F}(0+, \hat{L})=0, \quad \hat{F}^{\prime}(0+, \hat{L})=0 .
$$

Now, we have four equations for four unknowns $A_{1}, A_{2}, U$ and $L$. Hence, in principle, we can derive the value function $\hat{F}(0+, v)$ by solving the simultaneous equations.

In this case, following the ordinary algebraic calculation, it is readily shown that the coefficients $A_{1}, A_{2}$ are given as in Proposition 3. Also, we obtain

$$
\begin{aligned}
& \frac{\hat{L}^{-\gamma_{1}}}{\gamma_{2}-\gamma_{1}}\left(\frac{\eta \hat{L}\left(\gamma_{2}-1\right)}{r-\mu_{v}}+\gamma_{2} \frac{c}{r}\right)=\frac{\hat{U}^{-\gamma_{1}}}{\gamma_{2}-\gamma_{1}}\left(\frac{\eta \hat{U}\left(\gamma_{2}-1\right)}{r-\mu_{v}}+\left(\gamma_{2}-1\right) \hat{U}\right), \\
& \frac{\hat{L}^{-\gamma_{2}}}{\gamma_{1}-\gamma_{2}}\left(\frac{\eta \hat{L}\left(\gamma_{1}-1\right)}{r-\mu_{v}}+\gamma_{1} \frac{c}{r}\right)=\frac{\hat{U}^{-\gamma_{2}}}{\gamma_{1}-\gamma_{2}}\left(\frac{\eta \hat{U}\left(\gamma_{1}-1\right)}{r-\mu_{v}}+\left(\gamma_{1}-1\right) \hat{U}\right) .
\end{aligned}
$$

Suppose $\hat{U}=k \hat{L}$ and substitute this into (A.3). The lower threshold $\hat{L}$ is then derived as in (14). Also, by substituting $\hat{U}=k \hat{L}$ into (A.2), we obtain

$$
\hat{L}=\frac{\gamma_{2} c}{r} /\left\{k^{1-\gamma_{1}}\left(\gamma_{2}-1\right)\left(\frac{r-\mu_{v}+\eta}{r-\mu_{v}}\right)-\frac{\eta\left(\gamma_{2}-1\right)}{r-\mu_{v}}\right\}
$$

Equation (15) is derived at once from (14) and (A.4).

\section{B The Mella-Barral and Perraudin Model}

In this appendix, we show that our model is indeed an extension of the model considered in Mella-Barral and Perraudin (1997). To this end, we consider a special case of our model with

$$
\sigma_{v}=\mu_{v}=0, \quad \eta v:=w .
$$

Then, our model degenerates to a one-factor model with stochastic variable $P$, while the asset value $V$ becomes constant with $V(t)=V(0)=v$ for all $t \geq 0$. In order to make the difference between the one-factor model and our bivariate model explicit, we denote the value functions and thresholds in the one-factor model by using a subscript 1. 
First, substituting the specification given in (B.1) into the value function (2), we obtain the value of the pure equity firm as

$$
\begin{aligned}
W_{1}^{*}(p) & =\sup _{\tau_{0} \in \mathcal{T}_{0}} \mathbb{E}\left[\int_{0}^{\tau_{0}} \mathrm{e}^{-r t}(P(t)-w) \mathrm{d} t+\mathrm{e}^{-r \tau_{0}} v\right], \\
& = \begin{cases}\frac{p}{r-\mu_{p}}-\frac{w}{r}+\frac{w+r v}{(1-\beta) r}\left(\frac{p}{b_{1}^{*} v}\right)^{\beta}, & \text { for } p>b_{1}^{*} v, \\
v, & \text { for } p \leq b_{1}^{*} v,\end{cases}
\end{aligned}
$$

where $P(0)=p$ and the liquidation threshold is given by $b_{1}^{*} v$ with

$$
b_{1}^{*}=\frac{\beta}{\beta-1} \frac{w / v+r}{r}\left(r-\mu_{p}\right) .
$$

Next, substituting (B.1) into (7), we obtain the equity value of the levered firm as

$$
\hat{F}_{1}(p)=\sup _{\tau_{1}, \tau_{2} \in \mathcal{T}} \mathbb{E}\left[\int_{0}^{\tau_{1} \wedge \tau_{2}} \mathrm{e}^{-r t}(P(t)-w-c) \mathrm{d} t+\mathbf{1}_{\left\{\tau_{1}>\tau_{2}\right\}} \mathrm{e}^{-r \tau_{2}} \max \left\{v-\frac{c}{r}, 0\right\}\right] .
$$

In the following, we consider the two cases, $v \leq c / r$ and $v>c / r$.

When $v \leq c / r$, the debt is risky and there is the possibility of voluntary default. Hence, the equity value is obtained as

$$
\begin{aligned}
\hat{F}_{1}(p) & =\sup _{\tau_{1} \in \mathcal{T}_{0}} \mathbb{E}\left[\int_{0}^{\tau_{1}} \mathrm{e}^{-r t}(P(t)-w-c) \mathrm{d} t\right], \\
& = \begin{cases}\frac{p}{r-\mu_{p}}-\frac{w+c}{r}+\frac{w+c}{(1-\beta) r}\left(\frac{p}{\hat{K}_{1} v}\right)^{\beta}, & \text { for } p>\hat{K}_{1} v, \\
0, & \text { for } p \leq \hat{K}_{1} v,\end{cases}
\end{aligned}
$$

where the default threshold is given by $\hat{K}_{1} v$ with

$$
\hat{K}_{1}=\frac{\beta}{\beta-1} \frac{w+c}{r v}\left(r-\mu_{p}\right) .
$$

On the other hand, when $v>c / r$, the debt is safe and equity holders prefer to liquidate the firm rather than default in order to receive the residual value. It follows that

$$
\begin{aligned}
\hat{F}_{1}(p) & =\sup _{\tau_{2} \in \mathcal{T}_{0}} \mathbb{E}\left[\int_{0}^{\tau_{2}} \mathrm{e}^{-r t}(P(t)-w-c) \mathrm{d} t+\mathrm{e}^{-r \tau_{2}}\left(v-\frac{c}{r}\right)\right], \\
& = \begin{cases}\frac{p}{r-\mu_{p}}-\frac{w+c}{r}+\frac{w+r v}{(1-\beta) r}\left(\frac{p}{\hat{K}_{1} v}\right)^{\beta}, & \text { for } p>\hat{K}_{1} v, \\
v-\frac{c}{r}, & \text { for } p \leq \hat{K}_{1} v,\end{cases}
\end{aligned}
$$

where the liquidation threshold is given by $\hat{K}_{1} v$ with

$$
\hat{K}_{1}=\frac{\beta}{\beta-1} \frac{w / v+r}{r}\left(r-\mu_{p}\right)=b_{1}^{*},
$$


which coincides with the liquidation threshold for the pure equity firm given in (B.2). Therefore, we obtain for $v>c / r$

$$
\hat{F}_{1}(p)=W_{1}^{*}(p)-\frac{c}{r}
$$

Similarly, substituting (B.1) into (16), we obtain the value of the pure equity firm taken over by debt holders as

$$
\begin{aligned}
X_{1}(p) & =\sup _{\tau_{3} \in \mathcal{T}_{0}} \mathbb{E}\left[\int_{0}^{\tau_{3}} \mathrm{e}^{-r t}\left(\xi P(t)-\xi_{0} w\right) \mathrm{d} t+\mathrm{e}^{-r \tau_{3}} v\right], \\
& = \begin{cases}\frac{\xi p}{r-\mu_{p}}-\frac{\xi_{0} w}{r}+\frac{\xi_{0} w+r v}{(1-\beta) r}\left(\frac{p}{\underline{b}_{1} v}\right)^{\beta}, & \text { for } p>\underline{b}_{1} v, \\
v, & \text { for } p \leq \underline{b}_{1} v,\end{cases}
\end{aligned}
$$

where $\xi_{0}>1$ is the efficiency loss associated with cost and the liquidation threshold is given by $\underline{b}_{1} v$ with

$$
\underline{b}_{1}=\frac{\beta}{\beta-1} \frac{\xi_{0} w / v+r}{r} \frac{r-\mu_{p}}{\xi}
$$

The debt value can be now obtained for each case. When $v \leq c / r$, the debt is risky and its value is given by

$$
\begin{aligned}
\hat{D}_{1}(p) & =\mathbb{E}\left[\int_{0}^{\tau_{1}} \mathrm{e}^{-r t} c \mathrm{~d} t+\mathrm{e}^{-r \tau_{1}} X\left(P\left(\tau_{1}\right)\right)\right], \\
& = \begin{cases}\frac{c}{r}+\left(X\left(\hat{K}_{1}\right)-\frac{c}{r}\right)\left(\frac{p}{\hat{K}_{1}}\right)^{\beta}, & \text { for } p>\hat{K}_{1}, \\
X_{1}(p), & \text { for } p \leq \hat{K}_{1} .\end{cases}
\end{aligned}
$$

On the other hand, when $v>c / r$, the debt is safe and its value is indeed obtained as

$$
\hat{D}_{1}(p)=\mathbb{E}\left[\int_{0}^{\tau_{2}} \mathrm{e}^{-r t} c \mathrm{~d} t+\mathrm{e}^{-r \tau_{2}} \frac{c}{r}\right]=\frac{c}{r}
$$

Finally, we obtain the total firm value from $\hat{W}_{1}(p)=\hat{F}_{1}(p)+\hat{D}_{1}(p)$ for each case. When the debt is risky $(v \leq c / r)$, the firm value is obtained as

$$
\hat{W}_{1}(p)= \begin{cases}\frac{p}{r-\mu_{p}}-\frac{w}{r}+\left(X\left(\hat{K}_{1}\right)-\frac{p}{r-\mu_{p}}+\frac{w}{r}\right)\left(\frac{p}{\hat{K}_{1} v}\right)^{\beta}, & \text { for } p>\hat{K}_{1} v \\ X_{1}(p), & \text { for } p \leq \hat{K}_{1} v\end{cases}
$$

while it is given by

$$
\hat{W}_{1}(p)=\hat{F}_{1}(p)+\hat{D}_{1}(p)=W_{1}^{*}(p)
$$

when the debt is safe $(v>c / r)$. These results coincide with the results obtained in Mella-Barral and Perraudin (1997). 


\section{Linear Complementarity Formulation}

Because we consider a fixed coupon payment $c$, there seems no analytical means to solve the PDE (9) with value-matching and smooth-pasting conditions (10)-(11). In this appendix, we explain how to solve the PDE (9) numerically. To this end, the key ingredients are the change-of-variable technique and the linear complementarity formulation.

First, the linear complementarity formulation of the problem (9) is given by

$$
(\mathcal{A} \hat{F}(p, v)+p-\eta v-c) h(v) \geq 0, \quad \mathcal{A} \hat{F}(p, v)+p-\eta v-c \geq 0, \quad h(v) \geq 0,
$$

where

$$
h(v)=\max \left\{v-\frac{c}{r}, 0\right\},
$$

with the initial boundary conditions for $\hat{F}(p, 0+)$ and $\hat{F}(0+, v)$, which have been obtained in Propositions 2 and 3, respectively, and the condition that

$$
\hat{F}(p, v) \rightarrow\left\{\begin{array}{ll}
\frac{p}{r-\mu_{p}}-\frac{\eta v}{r-\mu_{v}}, & \text { for } \frac{p}{v}>b^{*}, \\
v, & \text { for } \frac{p}{v} \leq b^{*},
\end{array} \quad \text { as } p \rightarrow \infty \text { or } v \rightarrow \infty\right.
$$

which has been discussed in Section 2.3.1.

Second, we use the change-of-variable technique with the above boundary conditions. That is, define

$$
x=\frac{p}{p+1}, \quad y=\frac{v}{v+1}
$$

and set

$$
G(x, y)=(1-x)(1-y) \hat{F}(p, v) .
$$

Note that, as $p, v \rightarrow 0$, we have $x, y \rightarrow 0$, while $x, y \rightarrow 1$ as $p, v \rightarrow \infty$, respectively. Hence, the state space for $(x, y)$ is given by $(0,1) \times(0,1)$.

The linear complementarity problem (C.1) can be written in terms of $x$ and $y$, after tedious algebra, as

$$
\tilde{\mathcal{A}} G(x, y) \cdot g(p, v) \geq 0, \quad \tilde{\mathcal{A}} G(x, y) \geq 0, \quad g(x, y) \geq 0
$$

where

$$
\begin{aligned}
\tilde{\mathcal{A}} G(x, y)= & \frac{1}{2} \sigma_{p}^{2} x^{2}(1-x)^{2} G_{x x}+\left\{\mu_{p} x(1-x)+\sigma_{p} \sigma_{v} \rho(1-x) x y\right\} G_{x} \\
+ & \frac{1}{2} \sigma_{v}^{2} y^{2}(1-y)^{2} G_{y y}+\left\{\mu_{v} y(1-y)+\sigma_{p} \sigma_{v} \rho(1-y) x y\right\} G_{y} \\
+ & \sigma_{p} \sigma_{v} \rho x y(1-x)(1-y) G_{x y}+\left\{\mu_{x} x+\mu_{y} y+\sigma_{p} \sigma_{v} \rho x y\right\} G \\
& +x(1-y)-\eta y(1-x)-c(1-x)(1-y),
\end{aligned}
$$

and where

$$
g(x, y)=(1-x)(1-y) h(v)=\max \left\{(1-x) y-\frac{c}{r}(1-x)(1-y), 0\right\},
$$


with the initial boundary conditions

$$
G(0+, y)=(1-y) \hat{F}\left(0+, \frac{y}{1-y}\right), \quad G(x, 0+)=(1-x) \hat{F}\left(\frac{x}{1-x}, 0+\right),
$$

and the boundary condition

$$
\begin{cases}\lim _{y \rightarrow 1} G(x, y)=1-x, & \text { for } x \geq 1 \\ \lim _{x \rightarrow 1} G(x, y)=\frac{1-y}{r-\mu_{p}}, & \text { for } y<1\end{cases}
$$

The boundary condition (C.6) can be derived by noting that the set $\{(p, v) \mid p / v=$ $b^{*}, p \rightarrow \infty$ or $\left.v \rightarrow \infty\right\} \in[0, \infty] \times[0, \infty]$ in the condition (C.2) can be replaced with the singleton $(x, y)=(1,1)$ for $G(x, y)$. Note that the function $G(x, y)$ is bounded in $(x, y)$

With a solution $G(x, y)$ at hand after solving the linear complementarity problem (C.4) with the boundary conditions (C.5)-(C.6), we perform the reversed change of variables by

$$
\hat{F}\left(\frac{x}{1-x}, \frac{y}{1-y}\right)=\frac{G(x, y)}{(1-x)(1-y)}
$$

in order to get the solution for the problem (9).

In actual numerical calculations, we divide the $(x, y)$ space into a regular finite mesh as usual, and take a finite-difference approximation of the linear complementarity equation (C.4). We then get a matrix form of Equation (C.4) with boundary conditions, that is known as a constrained linear problem. There exists a general means for solving such constrained linear problems, called the projected successive over-relaxation method. We simply follow Wilmott et al. (1993) to get an approximated solution for the problem (C.4).

\section{References}

Acharya, V., Huang, J.-Z., Subrahmanyam, M. G., and Sundaram, R. K. (2006). When does strategic debt-service matter? Economic Theory, 29, 363-378.

Anderson, R. W. and Sundaresan, S. M. (1996). The design and valuation of debt contracts. Review of Financial Studies, 9, 37-68.

Black, F. and Cox, J. C. (1976). Valuing corporate securities: Some effects of bond indenture provisions. Journal of Finance, 31, 351-367.

Black, F. and Scholes, M. (1973). The pricing options and corporate liabilities. Journal of Political Economy, 81, 637-654.

Brennan, M. J. and Schwartz, E. S. (1984). Optimal financial policy and firm valuation. Journal of Finance, 39, 593-607.

Collin-Dufresne, P. and Goldstein, R. (2001). Do credit spreads reflect stationary leverage ratios? Journal of Finance, 56, 1929-1957. 
Davydenko, S. A. and Strebulaev, I. A. (2007). Strategic actions and credit spreads: An empirical investigation. Journal of Finance, 62, 2633-2671.

Eom, Y., Helwege, J., and Huang, J. (2004). Structural models of corporate bond pricing: An empirical analysis. Review of Financial Studies, 17, 499-544.

Fan, H. and Sundaresan, S. M. (2000). Debt valuation, renegotiation, and optimal dividend policy. Review of Financial Studies, 13, 1057-1099.

Fleming, W. H. and Soner, H. M. (1993). Controlled Markov Processes and Viscosity Solutions. Springer, New York.

Geske, R. (1977). The valuation of corporate liabilities as compound options. Journal of Financial and Quantitative Analysis, 12, 541-552.

Hart, O. and Moore, J. (1994). A theory of debt based on the inalienability of human capital. Quarterly Journal of Economics, 109, 841-879.

Hart, O. and Moore, J. (1998). Default and renegotiation: A dynamic model of debt. Quarterly Journal of Economics, 113, 1-41.

Jensen, M. C. and Meckling, W. H. (1976). Theory of the firm: Managerial behavior, agency costs and ownership structure. Journal of Financial Economics, 3, 305360 .

Kijima, M. and Suzuki, T. (2001). A jump-diffusion model for pricing corporate debt securities in a complex capital structure. Quantitative Finance, 1, 611-620.

Lambrecht, B. M. and Myers, S. C. (2007). A theory of takeovers and disinvestment. Journal of Finance, 62, 809-845.

Leland, H. E. (1994). Corporate debt value, bond covenants, and optimal capital structure. Journal of Finance, 49, 1213-1252.

Leland, H. E. and Toft, K. B. (1996). Optimal capital structure, endogenous bankruptcy, and the term structure of credit spreads. Journal of Finance, 51, 987-1019.

Longstaff, F. A. and Schwartz, E. S. (1995). A simple approach to valuing risky fixed and floating rate debt. Journal of Finance, 50, 789-819.

Mella-Barral, P. (1999). The dynamics of default and debt reorganization. Review of Financial Studies, 12, 535-578.

Mella-Barral, P. and Perraudin, W. (1997). Strategic debt service. Journal of Finance, 52, 531-556.

Merton, R. C. (1974). On the pricing of corporate debt: The risk structure of interest rates. Journal of Finance, 29, 449-470.

Wilmott, P., Dewynne, J., and Howison, S. (1993). Option Pricing. Oxford Financial Press, Oxford. 


\section{Figures}

Figure 1: Default and liquidation boundaries for the base case

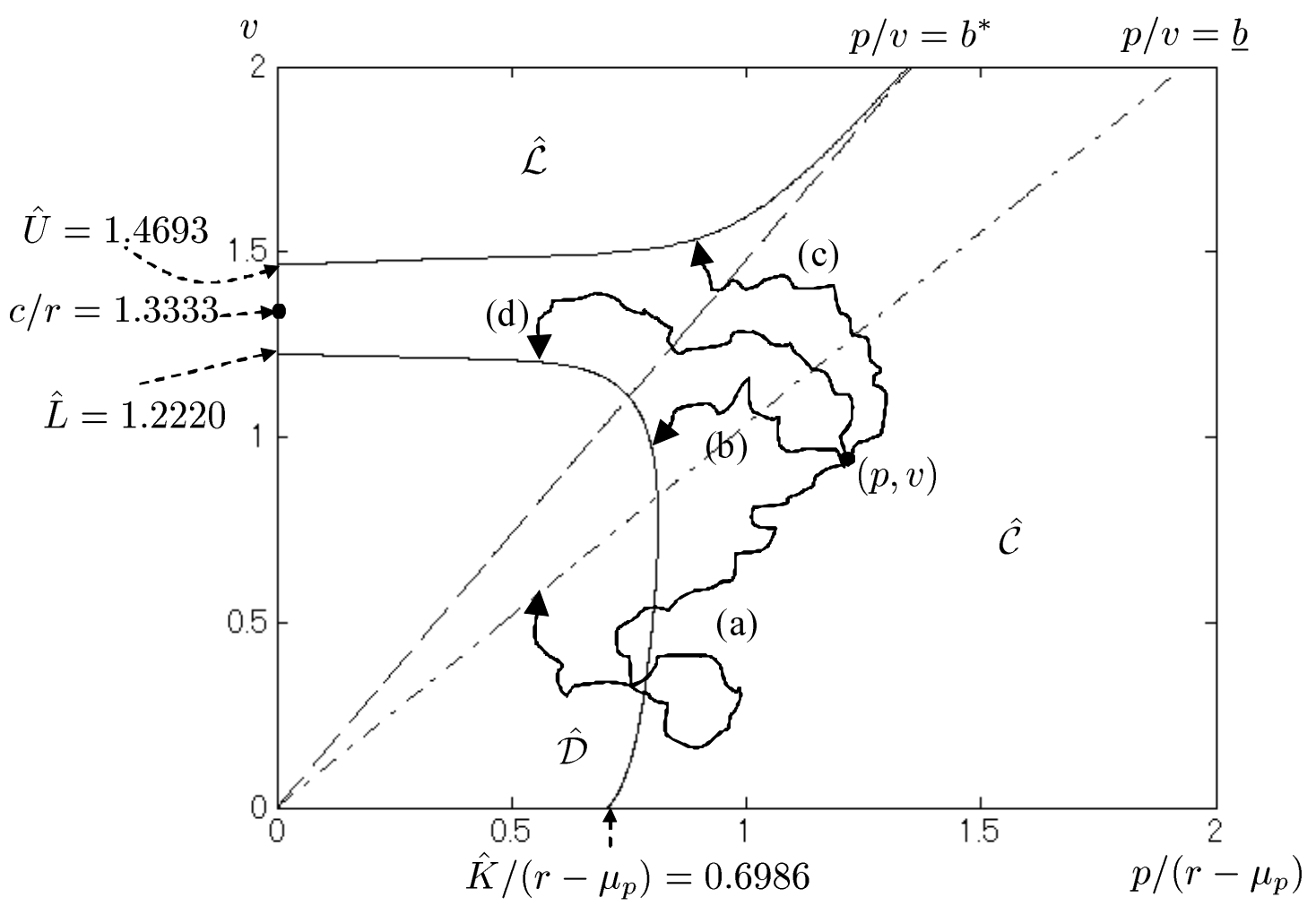

$\hat{\mathcal{L}}$ denotes the liquidation region, $\hat{\mathcal{D}}$ the default region, and $\hat{\mathcal{C}}$ the operating region. The default boundary $\hat{\mathcal{B}}_{C D}$ and liquidation boundary $\hat{\mathcal{B}}_{C L}$ are calculated by solving the free-boundary problem (9), where we employ the finite difference method explained in Appendix $\mathrm{C}$ with $1,000 \times 1,000$ meshes in order to draw smooth boundaries. The dashed and chained lines represent the straight lines $p / v=b^{*}$ and $p / v=\underline{b}$, respectively. The parameters are taken from Table 1 . Typical sample paths (a)-(d) are depicted to explain the default/liquidation mechanism in our model. Sample paths (a) and (b) correspond to early liquidation, while sample paths (c) and (d) correspond to late liquidation. 
Figure 2: Default and liquidation boundaries for the one-factor model

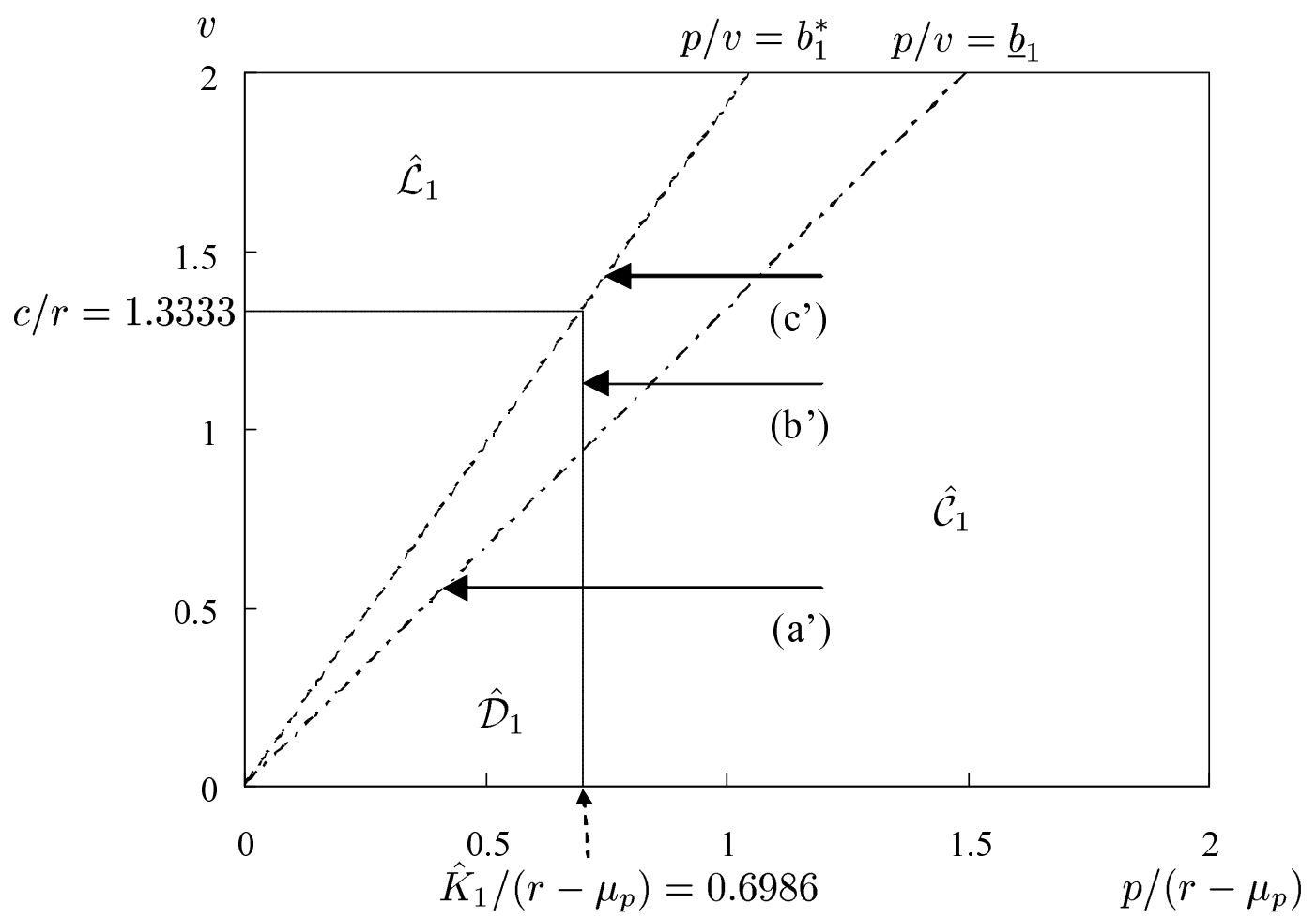

$\hat{\mathcal{L}}_{1}$ denotes the liquidation region, $\hat{\mathcal{D}}_{1}$ the default region, and $\hat{\mathcal{C}}_{1}$ the operating region. The default boundary $\mathcal{B}_{C_{1} D_{1}}$ between $\hat{\mathcal{C}}_{1}$ and $\hat{\mathcal{D}}_{1}$ is a straight line obtained in Appendix B. The dashed and chained lines represent the straight lines $p / v=b_{1}^{*}$ and $p / v=\underline{b}_{1}$, respectively. Typical sample paths (a'), (b') and (c') are appended to explain the default/liquidation mechanism in the special case. In this model, sample paths (a') and (b') correspond to early liquidation, and sample path (c') corresponds to liquidation of pure equity firm. There is no late liquidation. 
Figure 3: Equity values for the base case

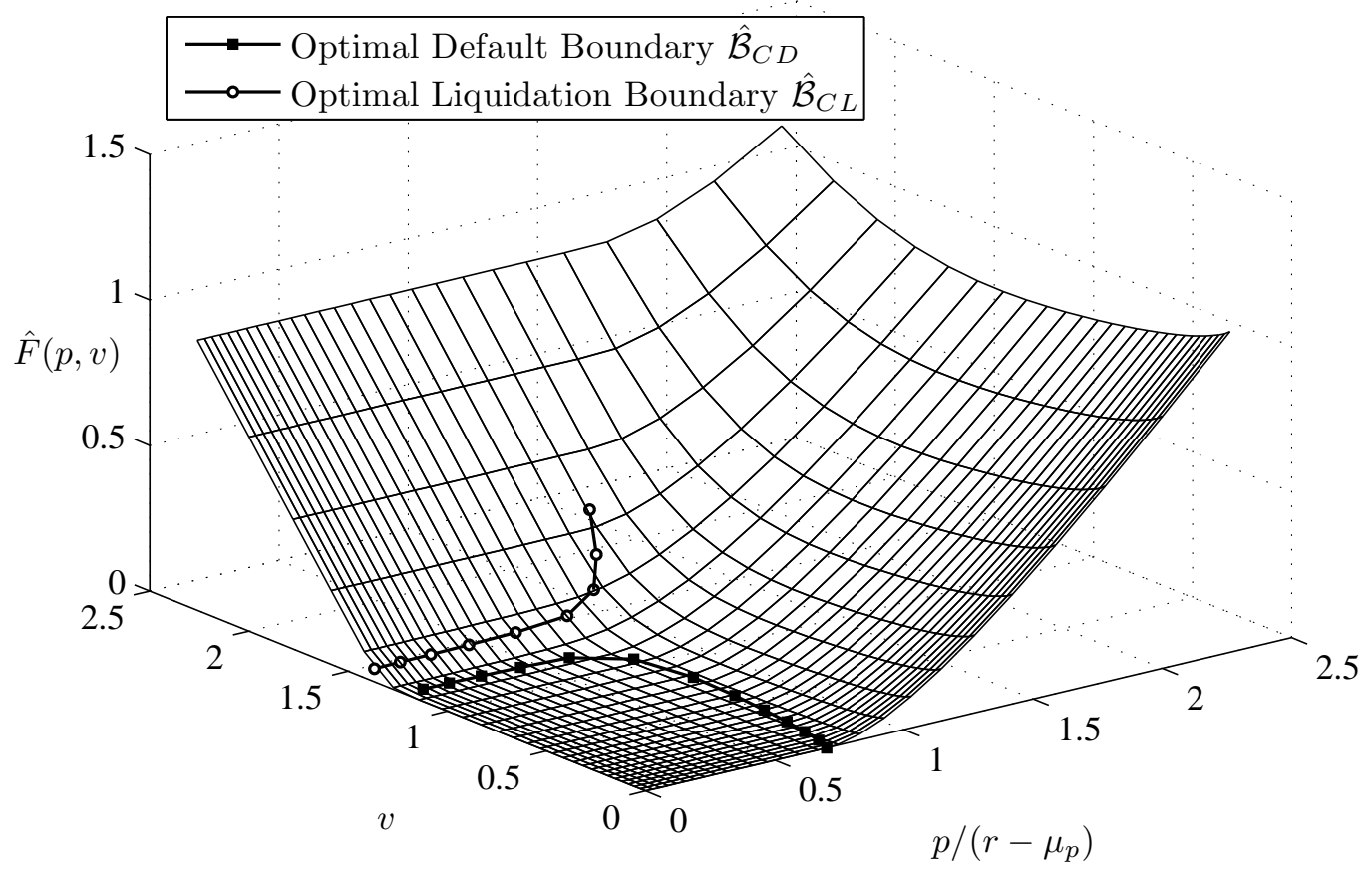

The surface plots the equity value $\hat{F}(p, v)$ for the base case (see Table 1 ). The line with black squares on the $(p, v)$-plane plots the optimal default boundary, while the line with white circles plots the optimal liquidation boundary. 
Figure 4: Debt values for the base case

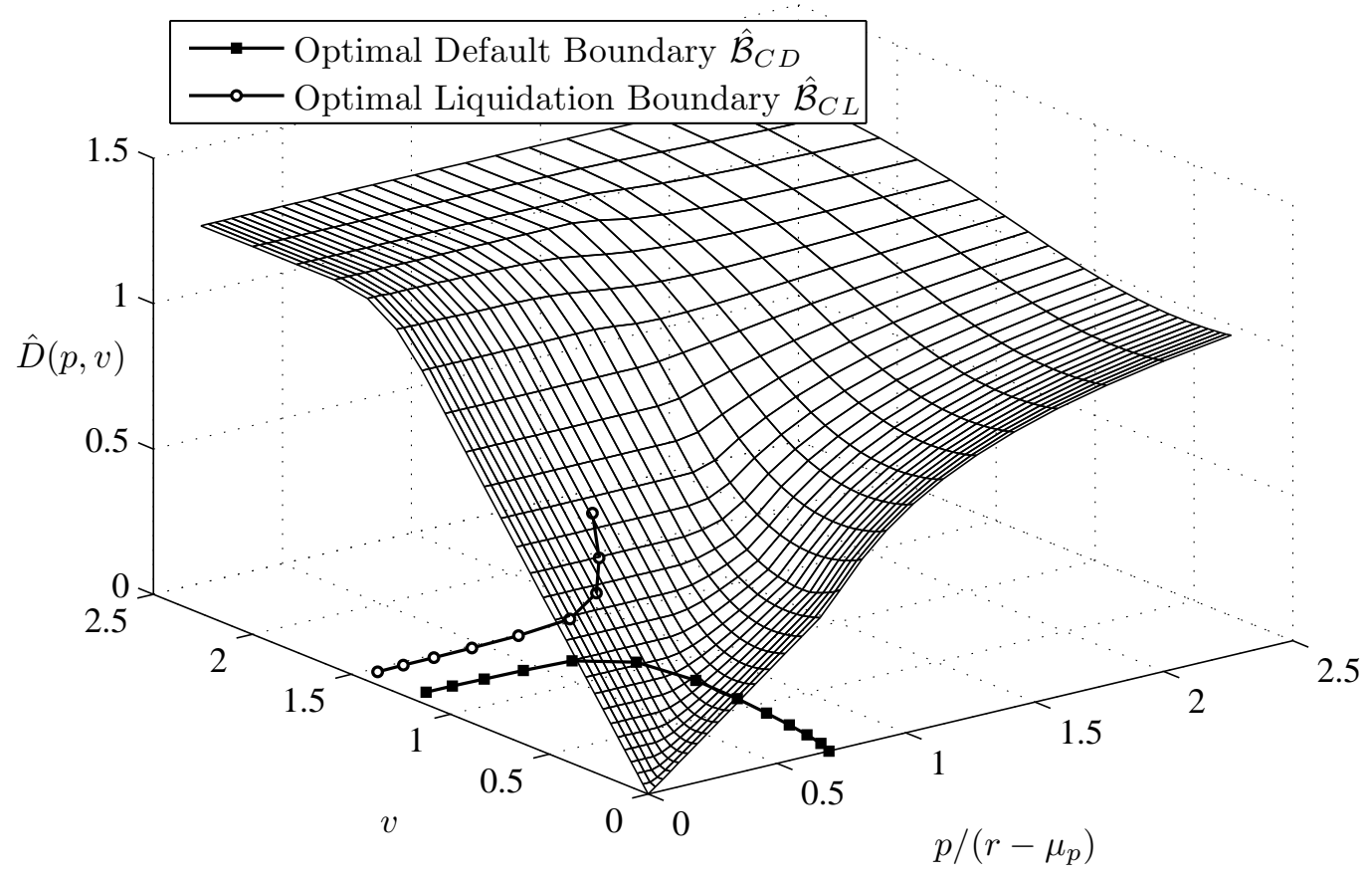

The surface plots the debt value $\hat{D}(p, v)$ for the base case (see Table 1$)$. The line with black squares on the $(p, v)$-plane plots the optimal default boundary, while the line with white circles plots the optimal liquidation boundary. 
Figure 5: Credit spreads for the base case

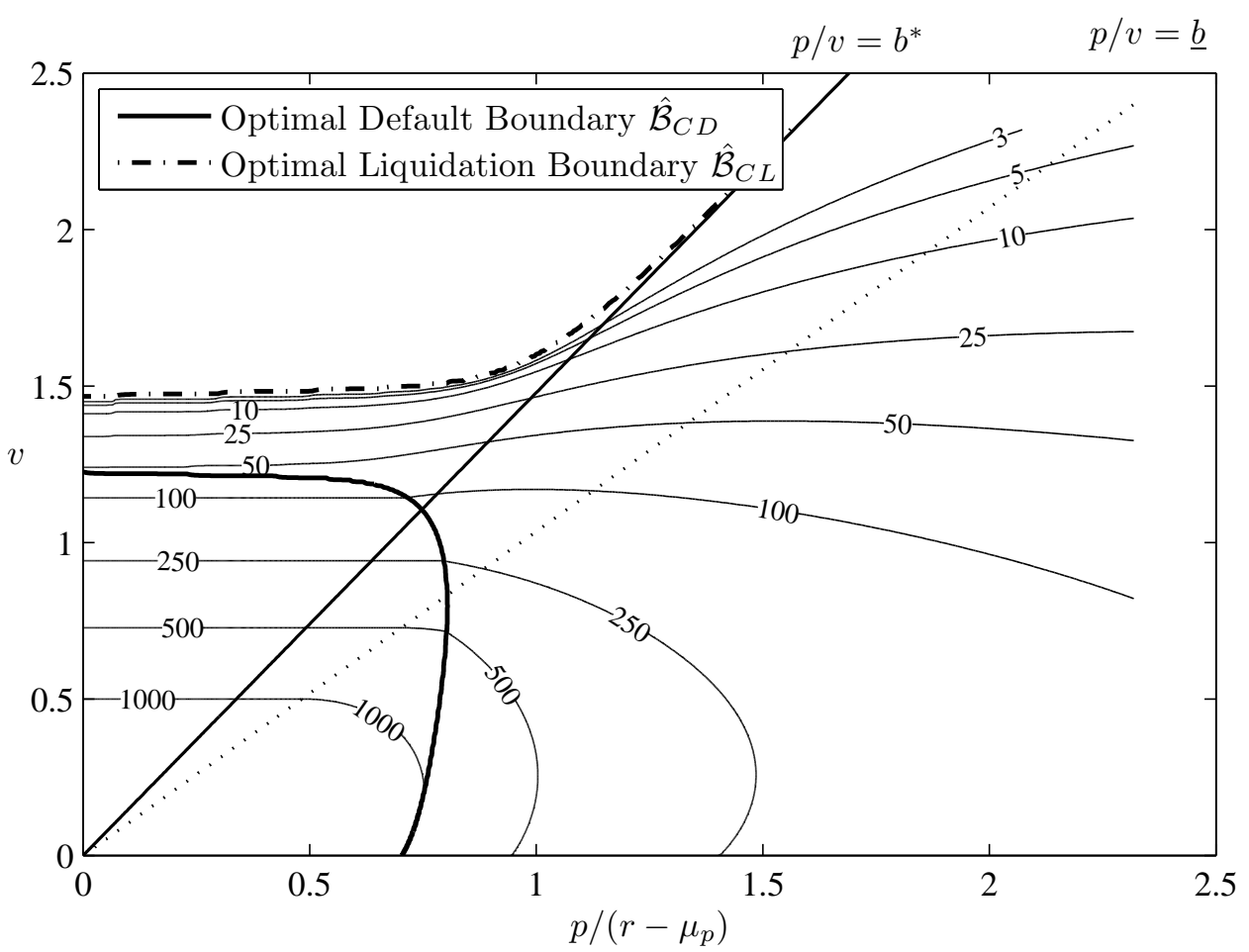

The numbers labeled on the contour lines represent the credit spreads (bp), $c / \hat{D}(p, v)-r$. The solid and dash-dotted curves plot the optimal default and liquidation boundaries, respectively. The solid and dotted lines depict the straight lines $p / v=b^{*}$ and $p / v=\underline{b}$, respectively. The parameters are taken from Table 1. A firm with few tangible assets has high credit spreads even if its EBIT is large. The credit spreads are constant with respect to $p$ in the region that debt holders decide to liquidate after they take over the firm. 
Figure 6: Impact of business risk $\sigma_{p}$ on equity value $\hat{F}(p, v)$

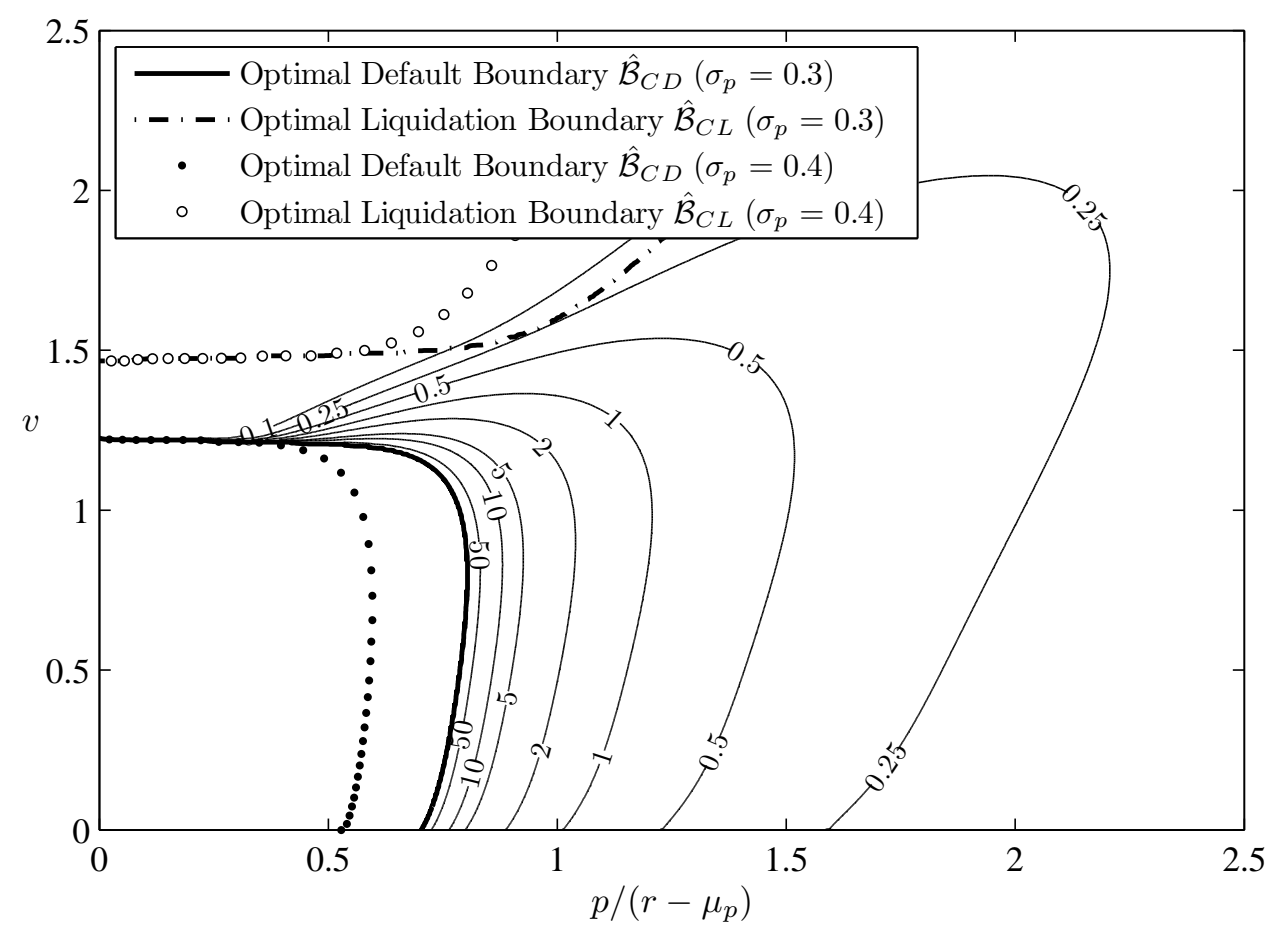

The numbers labeled on the contour lines represent the percentage change in the equity value when $\sigma_{p}$ changes from $30 \%$ (the base case) to $40 \%$, which shows the equity holders' incentive to raise the business risk. The bold lines show the optimal default boundary (solid line) and optimal liquidation boundary (dash-dotted line) for $\sigma_{p}=30 \%$, while the circles show the optimal default boundary (black circle) and optimal liquidation boundary (white circle) for $\sigma_{p}=40 \%$. The other parameters are taken from Table 1. Equity holders have a strong incentive to raise the business risk even on the brink of default in our model. 
Figure 7: Impact of business risk $\sigma_{p}$ on debt value $\hat{D}(p, v)$

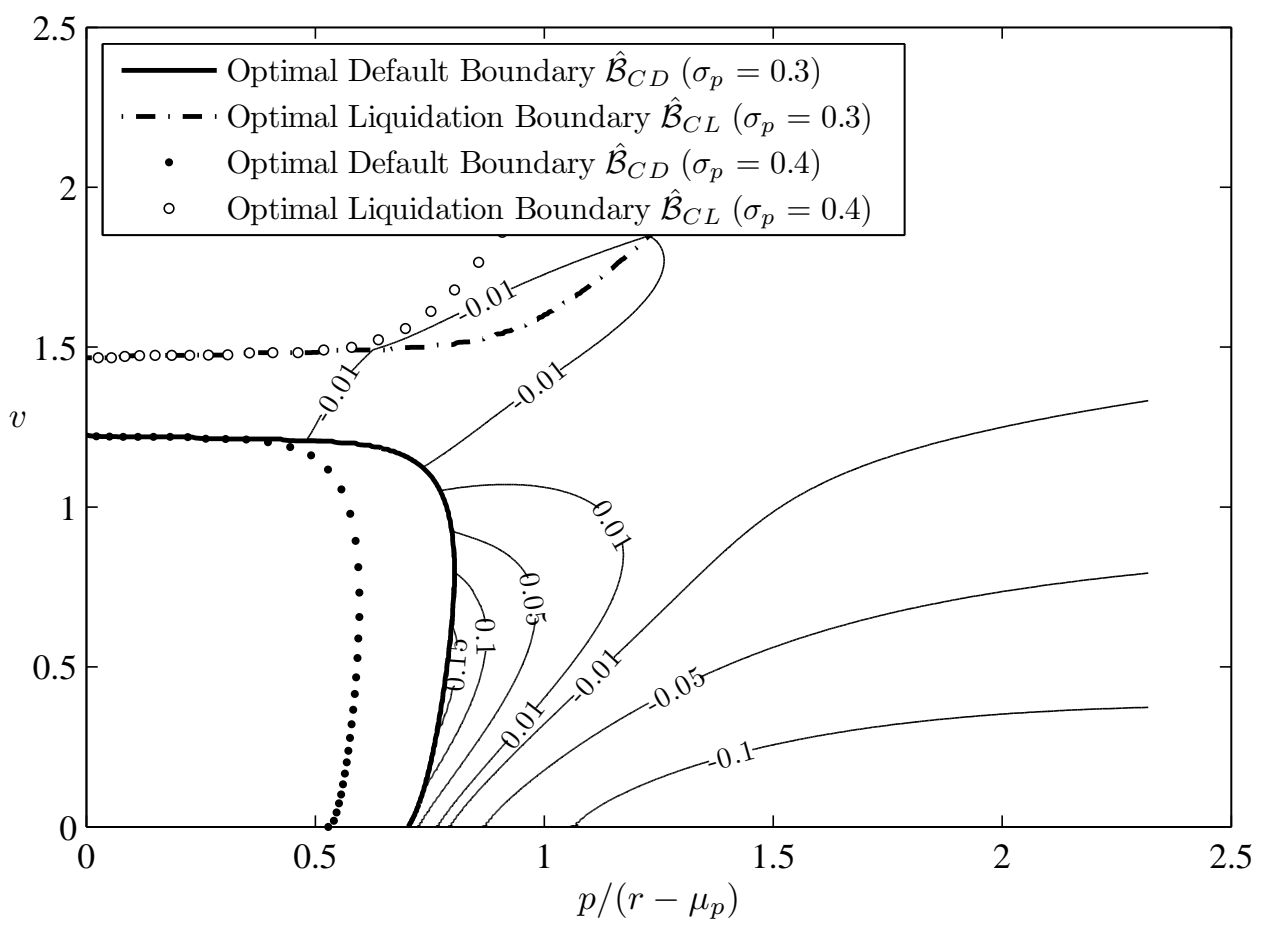

The numbers labeled on the contour lines represent the percentage change in the debt value when $\sigma_{p}$ changes from $30 \%$ (the base case) to $40 \%$, which shows the debt holders' incentive to raise the business risk. The other lines and parameters are the same as Figure 6 . On the brink of default with $v$ being less than unity, both equity holders and debt holders wish to increase the business risk. This anomaly is also observed in Leland (1994). 
Figure 8: Impact of collateral volatility $\sigma_{v}$ on equity value $\hat{F}(p, v)$

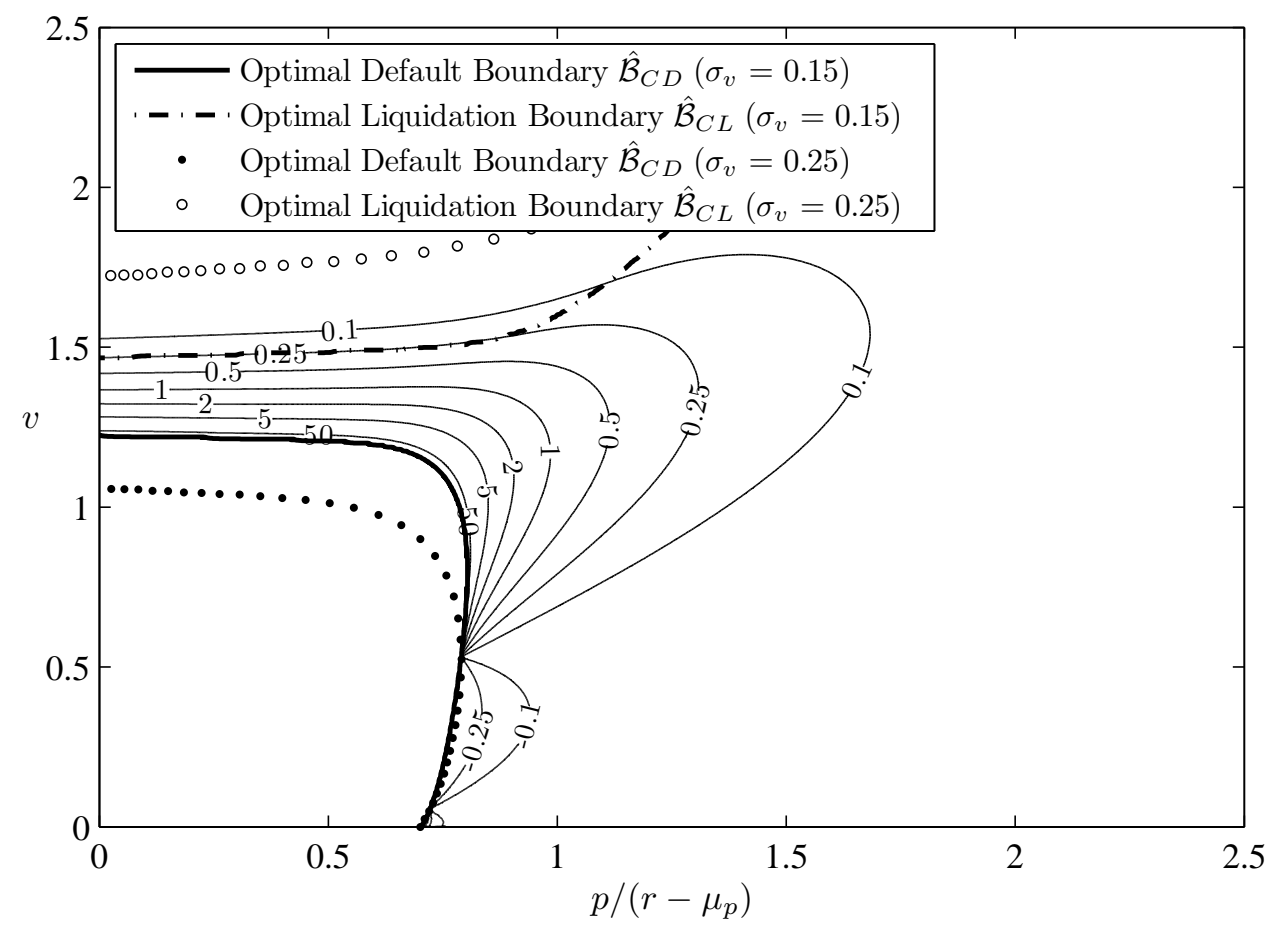

The numbers labeled on the contour lines represent the percentage change in the equity value when $\sigma_{v}$ changes from $15 \%$ (the base case) to $25 \%$, which shows the equity holders' incentive to raise the collateral volatility. The bold lines show the optimal default boundary (solid line) and optimal liquidation boundary (dash-dotted line) for $\sigma_{v}=15 \%$, while the circles show the optimal default boundary (black circle) and optimal liquidation boundary (white circle) for $\sigma_{v}=25 \%$. The other parameters are taken from Table 1. Equity holders have a strong incentive to increase risk $\sigma_{v}$ at the brink of default, while they have no incentive when the level of EBIT is sufficiently high. 
Figure 9: Impact of collateral volatility $\sigma_{v}$ on debt value $\hat{D}(p, v)$

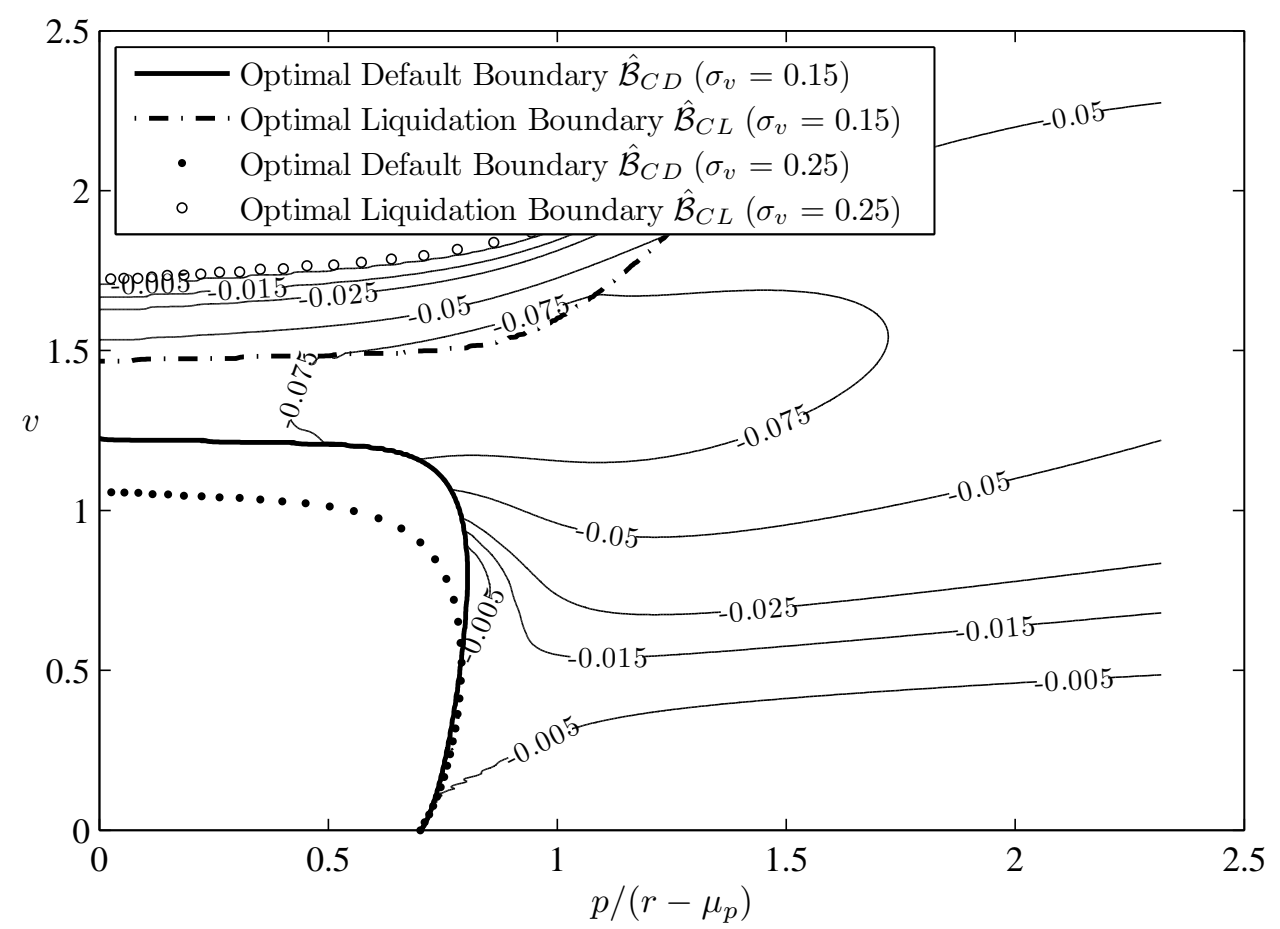

The numbers labeled on the contour lines represent the percentage change in the debt value when $\sigma_{v}$ changes from $15 \%$ (the base case) to $25 \%$, which shows the equity holders' incentive to raise the collateral volatility. The other lines and parameters are the same as Figure 8. Debt holders lose their value in the whole region. Anomaly at the brink of default does not occur in this risk shifting. 
Figure 10: Default, liquidation and renegotiation boundaries for the base case

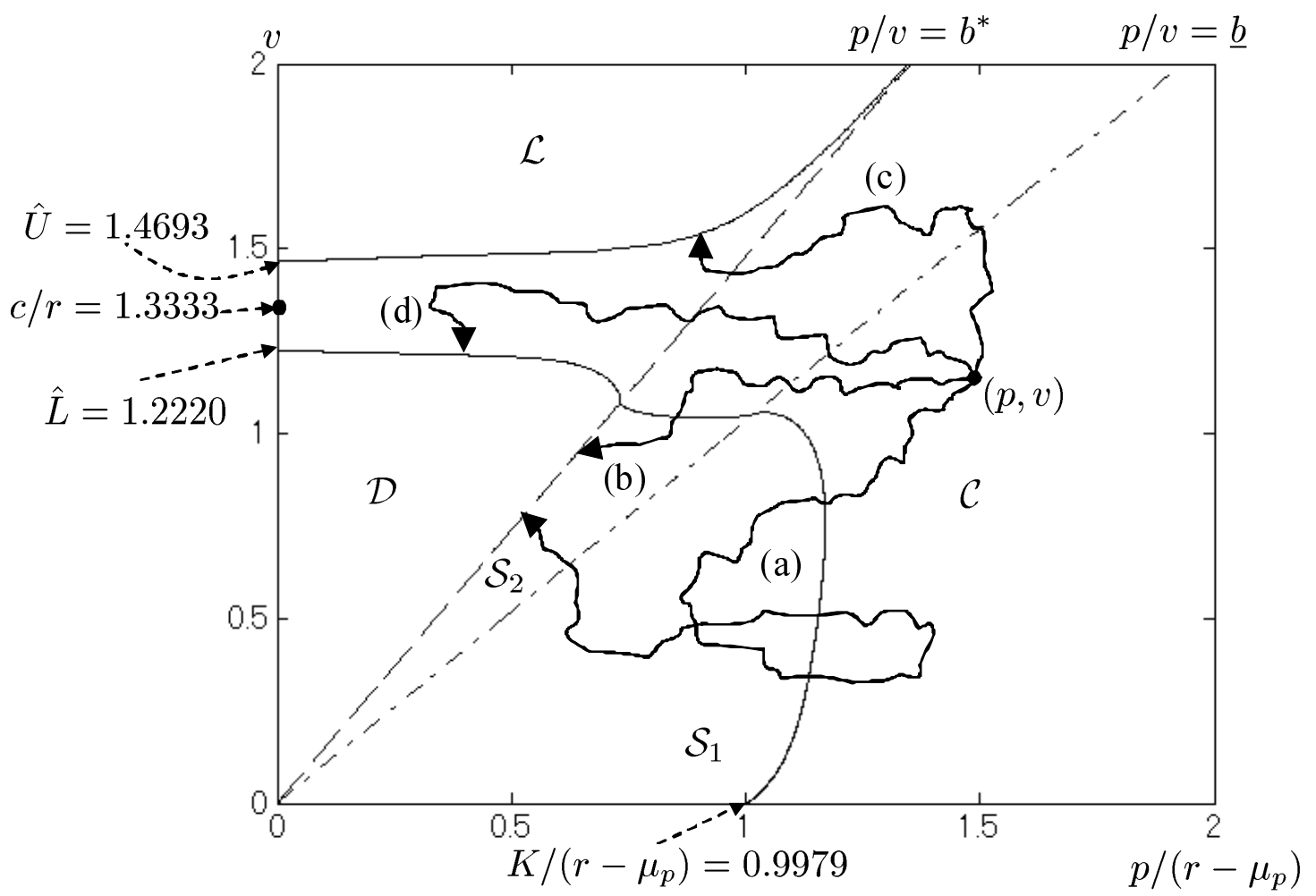

$\mathcal{L}$ denotes the liquidation region, $\mathcal{D}$ the default region, $\mathcal{C}$ the operating region, and $\mathcal{S}$ the region for renegotiation. The renegotiation region $\mathcal{S}$ is further divided into $\mathcal{S}_{1}$ with service flow $\xi p-\eta v$ and $\mathcal{S}_{2}$ with service flow $\left(r-\mu_{v}\right) v$. The renegotiation boundary $\mathcal{B}_{C S}$, default boundary $\mathcal{B}_{C D}$ and liquidation boundary $\mathcal{B}_{C L}$ are calculated by solving the free-boundary problem (22), where we employ the finite difference method explained in Appendix $C$ with $1,000 \times 1,000$ meshes in order to draw smooth boundaries. The dashed and chained lines represent the straight lines $p / v=b^{*}$ and $p / v=\underline{b}$, respectively. Typical sample paths (a)-(d) are added to explain the renegotiation/default/liquidation mechanism in our model. In our model, sample paths (a) and (b) correspond to strategic default, sample path (d) corresponds to liquidity default, and sample path (c) corresponds to liquidation. 
Figure 11: Contribution of strategic debt service to credit spreads $(\xi=0.7)$

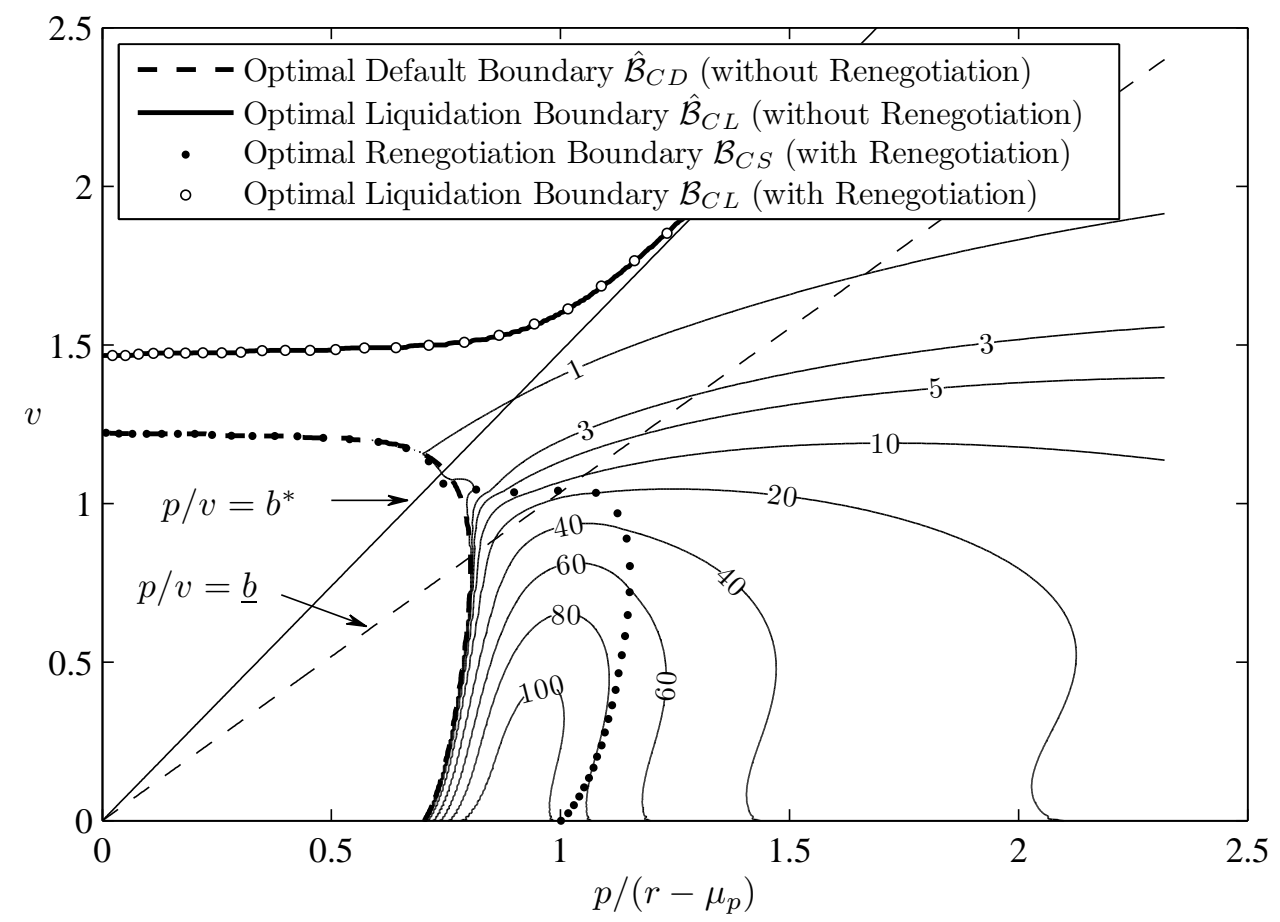

The numbers labeled on the contour lines represent the additional credit spreads (bp) due to debt renegotiation, $c(1 / D(p, v)-1 / \hat{D}(p, v))$, The bold dashed and solid lines plot the optimal default and liquidation boundaries without renegotiation, respectively, while the white and black circles plot the optimal liquidation and renegotiation boundaries with renegotiation, respectively. The thin solid and dotted lines depict the straight lines $p / v=b^{*}$ and $p / v=\underline{b}$, respectively. The parameters are taken from Table 1 . The additional credit spreads due to debt renegotiation are high when the value of tangible assets is low and the value of EBIT is small. Note however that they are significantly low compared to the existing theoretical results. 
Figure 12: Contribution of strategic debt service to credit spreads $(\xi=0.5)$

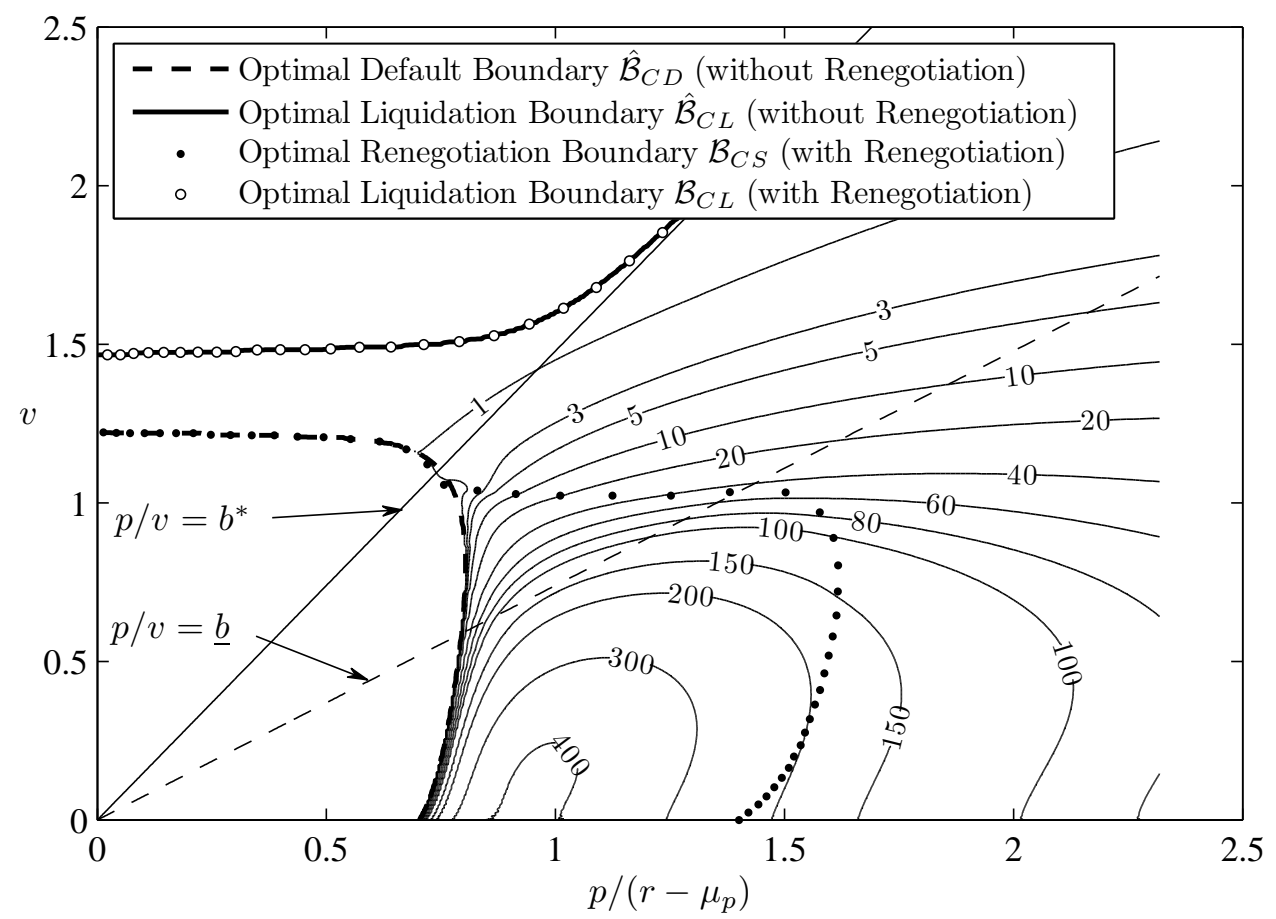

The numbers labeled on the contour lines represent the additional credit spreads (bp) due to debt renegotiation, when the efficiency loss is $\xi=0.5$. The other lines and parameters are the same as Figure 11. Through ample numerical experiments, we find that changes in credit spreads due to debt renegotiation are likely to be affected in large parts by the parameter $\xi$. 
Figure 13: Sensitivity of optimal boundaries due to the change in $\sigma_{v}$
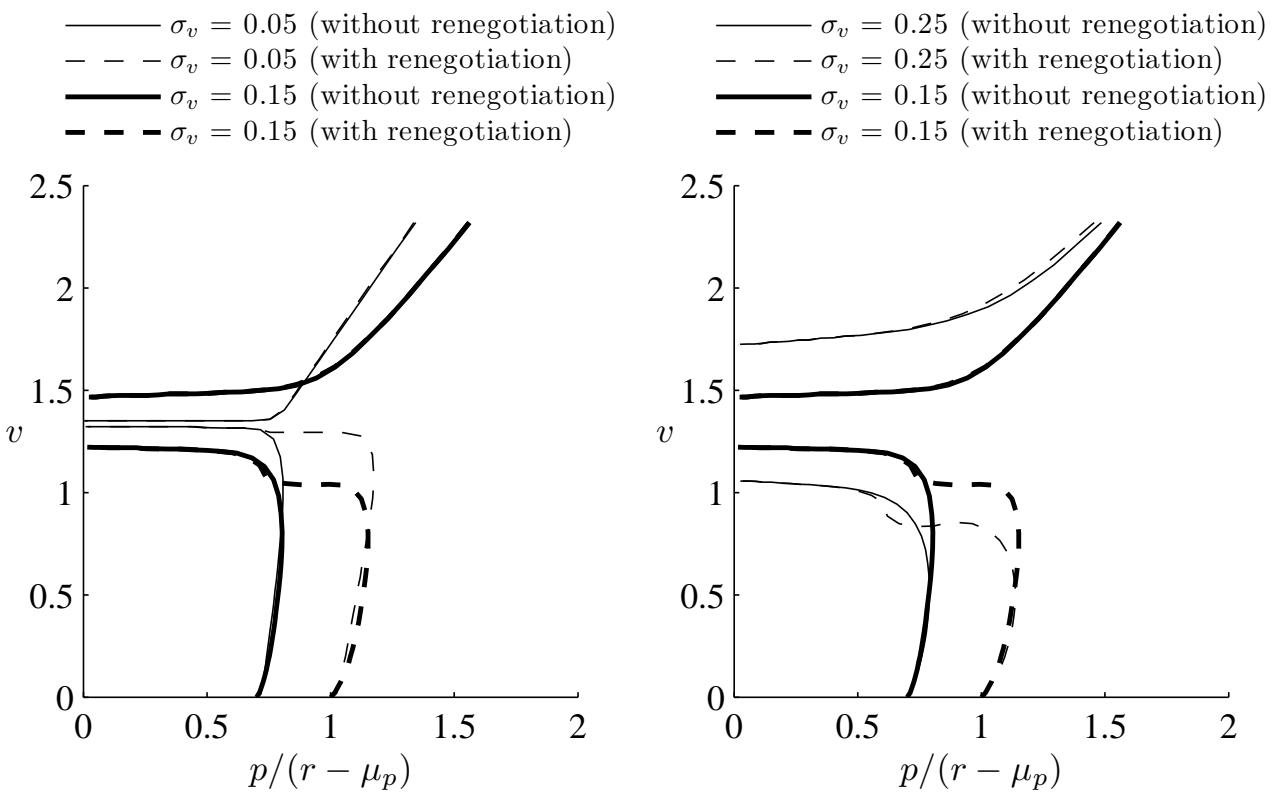

The left and right panels show the changes of the optimal boundaries with respect to the volatility of tangible assets from $\sigma_{v}=15 \%$ (the base case) to $5 \%$ and to $25 \%$, respectively. The solid and dashed lines depict the optimal boundaries without and with renegotiation, respectively. The bold lines represent the optimal liquidation boundaries (upper-left) and the optimal default boundaries (lower-left) for $\sigma_{v}=15 \%$ in the both panels. The thin lines in the left and right panels depict the optimal boundaries for $\sigma_{v}=5 \%$ and $\sigma_{v}=25 \%$, respectively. The other parameters are taken from Table 1. As volatility $\sigma_{v}$ increases, the liquidation boundaries for the both case move upward for relatively small EBIT values, which gives equity holders a higher value of option to liquidate. As a result, the optimal default boundary $\hat{\mathcal{B}}_{C D}$ and renegotiation boundary $\mathcal{B}_{C S}$ move downward for higher volatility. 
Figure 14: Sensitivity of optimal boundaries due to the change in $\xi$

$---\xi=0.5$ (with renegotiation)

$\xi=0.7$ (without renegotiation)

- $-\boldsymbol{-} \xi=0.7$ (with renegotiation)

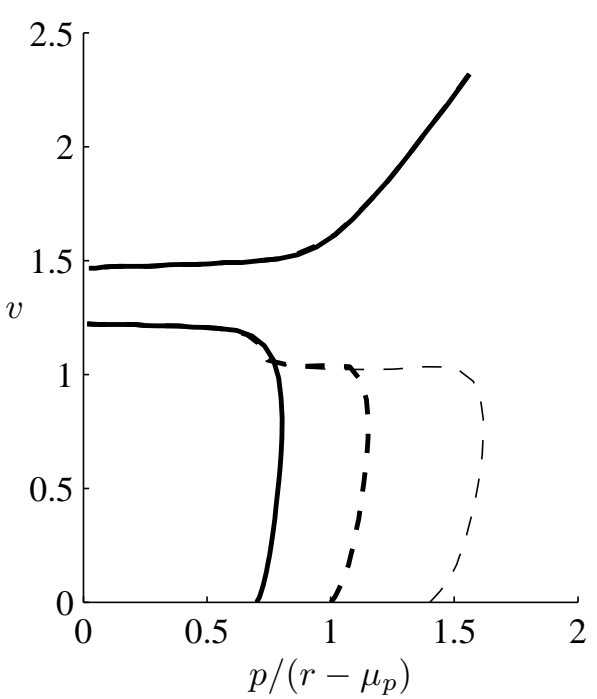

$---\xi=0.9$ (with renegotiation)

$\xi=0.7$ (without renegotiation)

$\mathbf{-}-\boldsymbol{-} \xi=0.7$ (with renegotiation)

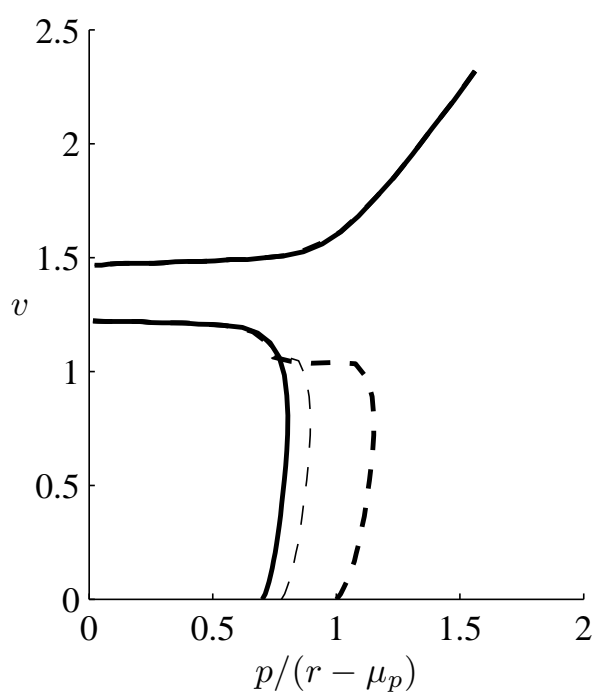

The left and right panels show the changes of the optimal boundaries with respect to the efficiency loss from $\xi=0.7$ (the base case) to 0.5 and to 0.9 , respectively. The solid and dashed lines depict the optimal boundaries without and with renegotiation, respectively. The bold lines represent the optimal liquidation boundaries (upper-left) and the optimal default boundaries (lower-left) for $\xi=0.7$ in the both panels. The thin lines in the left and right panels depict the optimal boundaries for $\xi=0.5$ and $\xi=0.9$, respectively. The other parameters are taken from Table 1 . The optimal renegotiation boundary $\mathcal{B}_{C S}$ is quite sensitive to $\xi$, which is consistent with earlier works. On the other hand, the liquidation boundary $\mathcal{B}_{C L}$ is not affected by $\xi$, as expected. 
Figure 15: Sensitivity of optimal boundaries due to the change in $\rho$
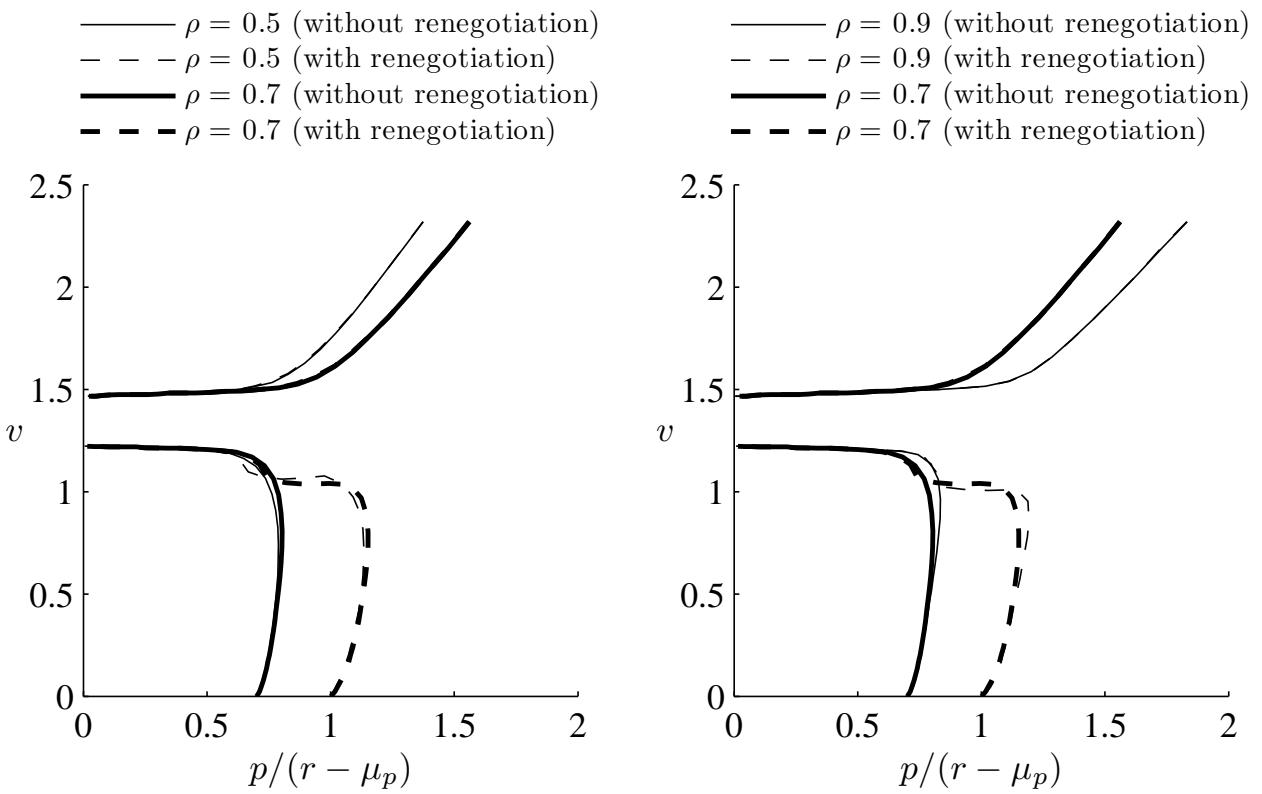

The left and right panels show the changes of the optimal boundaries with respect to the correlation from $\rho=0.7$ (the base case) to 0.5 and to 0.9 , respectively. The solid and dashed lines depict the optimal boundaries without and with renegotiation, respectively. The bold lines represent the optimal liquidation boundaries (upper-left) and the optimal default boundaries (lower-left) for $\rho=0.7$ in the both panels. The thin lines in the left and right panels depict the optimal boundaries for $\rho=0.5$ and $\rho=0.9$, respectively. The other parameters are taken from Table 1 . While the optimal boundary $\mathcal{B}_{C L}$ to liquidate the firm is very sensitive to the correlation, the impact of correlation on the boundary $\mathcal{B}_{C S}$ to enter renegotiation is very limited. 
Figure 16: Sensitivity of optimal boundaries due to the change in $\sigma_{p}$
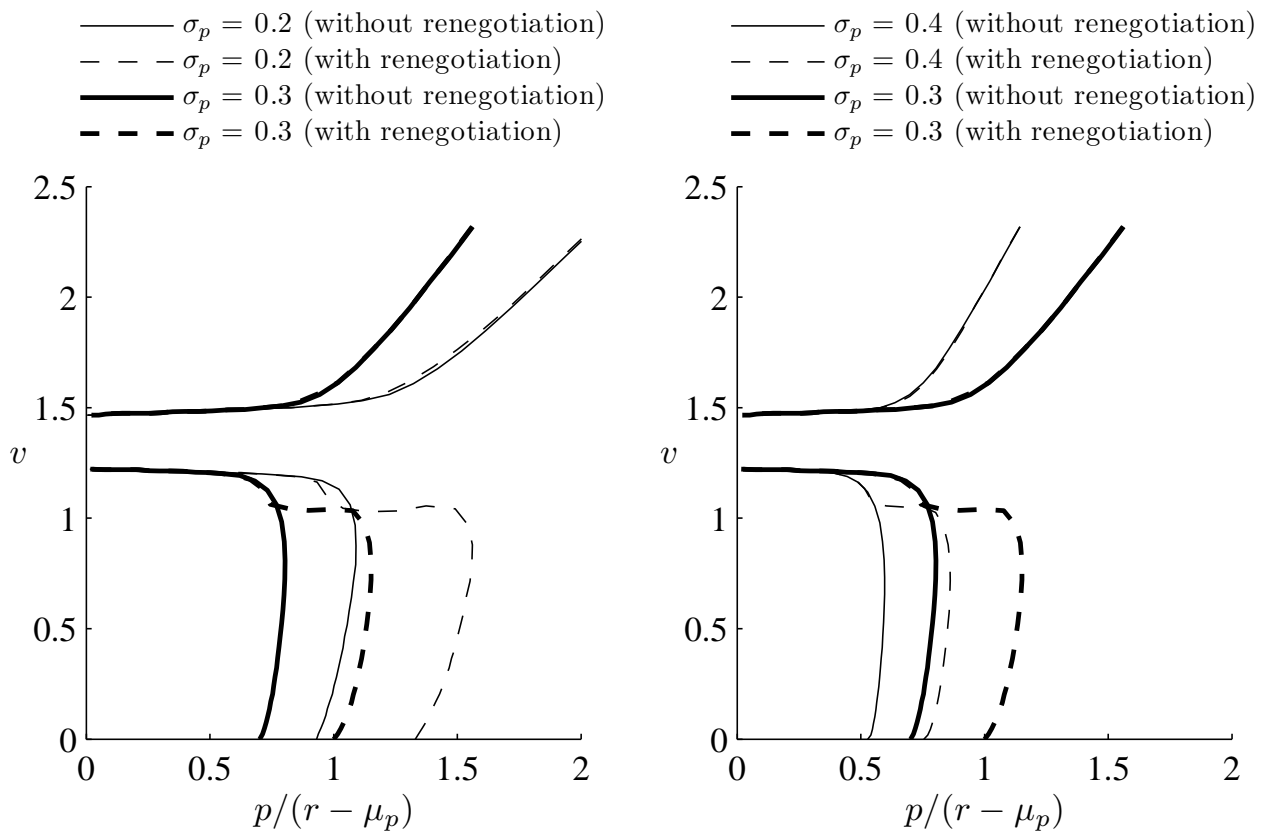

The left and right panels show the changes of the optimal boundaries with respect to the volatility of EBIT from $\sigma_{p}=30 \%$ (the base case) to $20 \%$ and to $40 \%$, respectively. The solid and dashed lines depict the optimal boundaries without and with renegotiation, respectively. The bold lines represent the optimal liquidation boundaries (upper-left) and the optimal default boundaries (lower-left) for $\sigma_{p}=30 \%$ in the both panels. The thin lines in the left and right panels depict the optimal boundaries for $\sigma_{p}=20 \%$ and $\sigma_{p}=40 \%$, respectively. The other parameters are taken from Table 1 . The volatility $\sigma_{p}$ of EBIT has a significant impact on the boundary $\mathcal{B}_{C S}$. 
Figure 17: Impact of business risk $\sigma_{p}$ on equity value $F(p, v)$

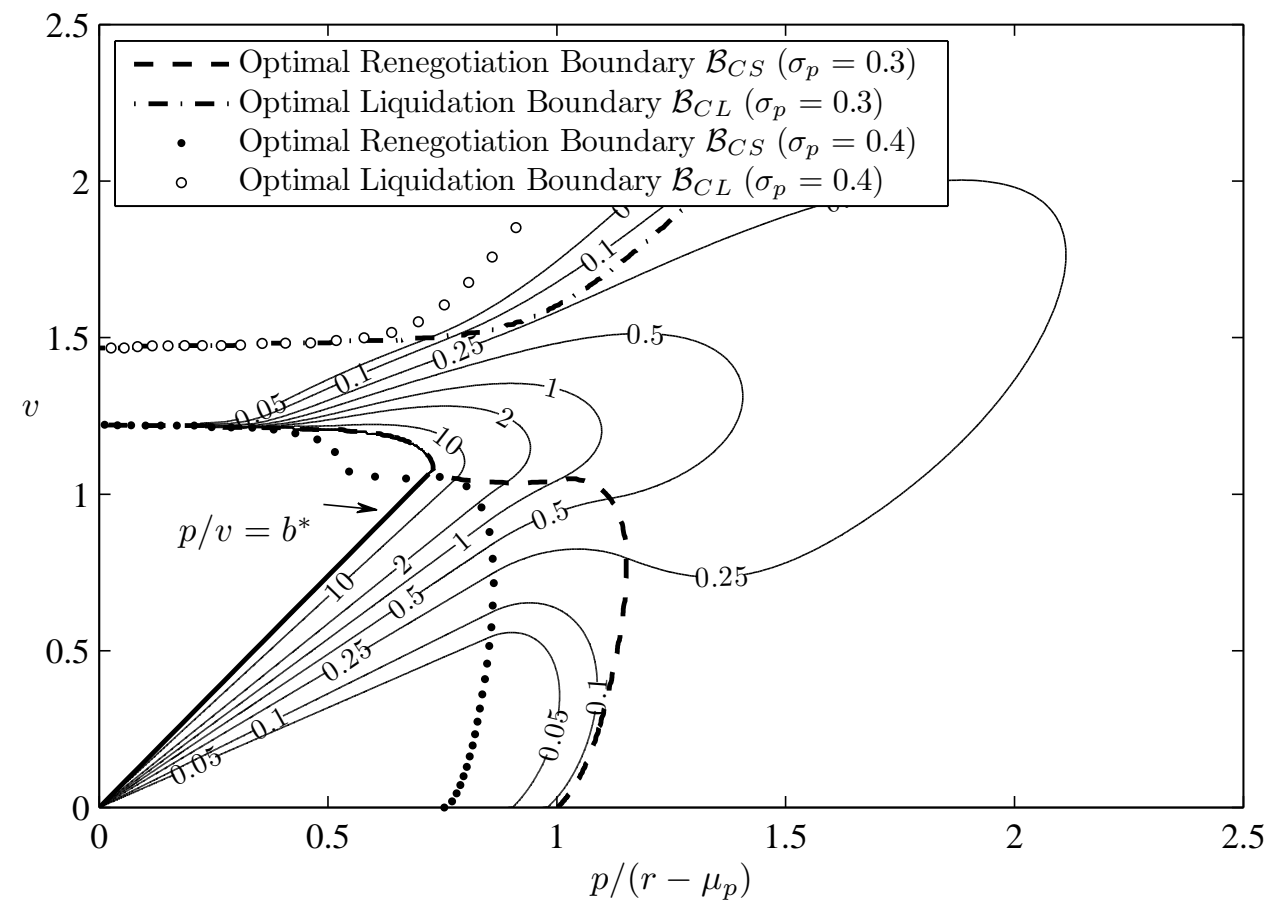

The numbers labeled on the contour lines represent the percentage change in the equity value when $\sigma_{p}$ changes from $30 \%$ (the base case) to $40 \%$, which shows the equity holders' incentive to raise the business risk $\sigma_{p}$. The bold lines show the optimal renegotiation boundary (dashed line) and optimal liquidation boundary (dash-dotted line) for $\sigma_{p}=30 \%$, while the circles show the optimal renegotiation boundary (black circle) and optimal liquidation boundary (white circle) for $\sigma_{p}=40 \%$. The other parameters are taken from Table 1. Equity holders have a strong incentive to raise the business risk, especially when default becomes almost certain. The default boundary is changed to the default boundary for the corresponding pure equity firm (the solid line) due to the introduction of debt renegotiation. Compared with the incentive for the case of no renegotiation (see Figure 6), debt renegotiation decreases the possibility of risk shifting. 
Figure 18: Impact of business risk $\sigma_{p}$ on debt value $D(p, v)$

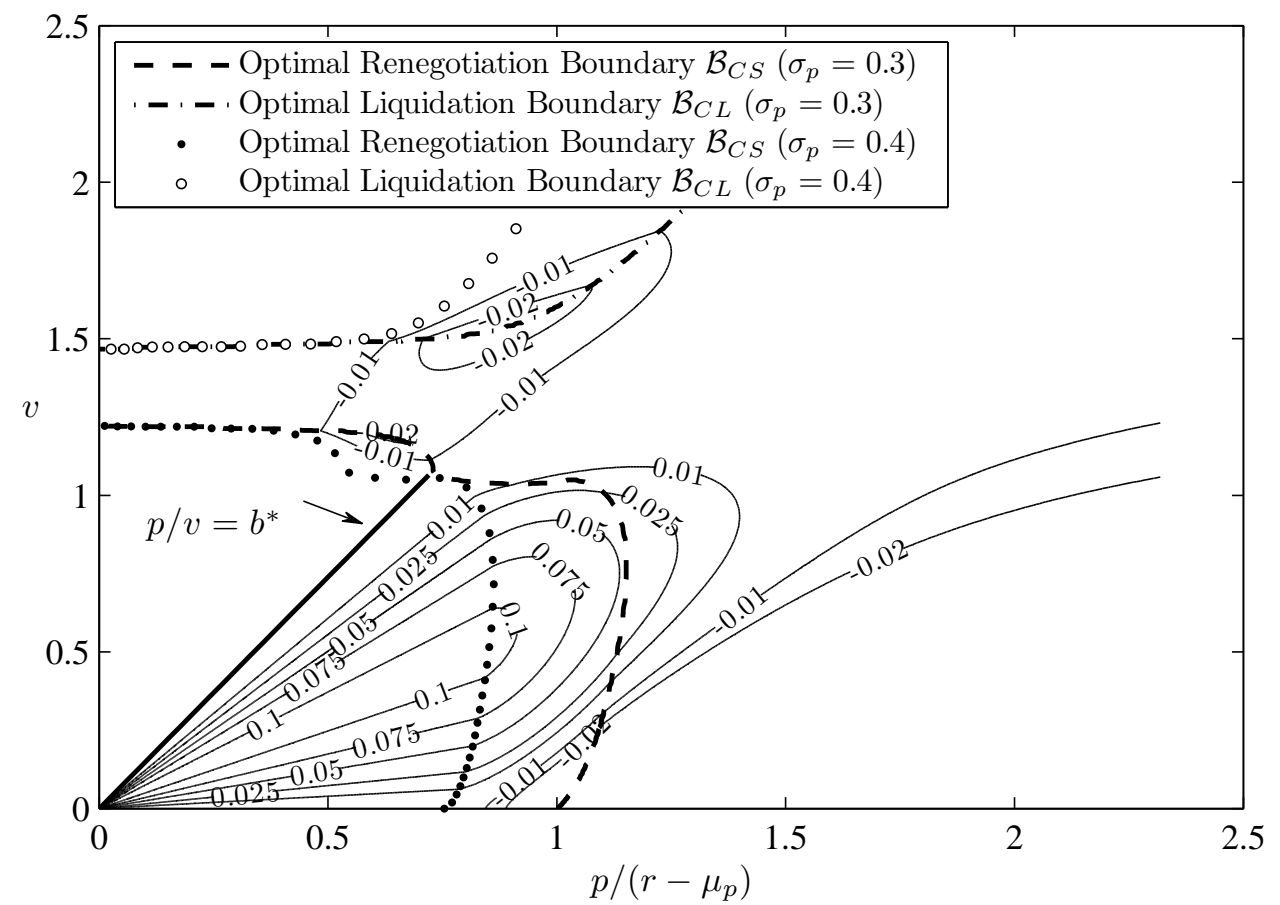

The numbers labeled on the contour lines represent the percentage change in the debt value when $\sigma_{p}$ changes from $30 \%$ (the base case) to $40 \%$, which shows the debt holders' incentive to raise the business risk $\sigma_{p}$. The bold lines show the optimal renegotiation boundary (dashed line) and optimal liquidation boundary (dash-dotted line) for $\sigma_{p}=30 \%$, while the circles show the optimal renegotiation boundary (black circle) and optimal liquidation boundary (white circle) for $\sigma_{p}=40 \%$. The other parameters are taken from Table 1 . When the value of EBIT is very high, debt holders have less incentive to raise the business risk. Debt holders have an incentive to raise the business risk in the region of renegotiation. However, the debt holders' incentive to raise the risk does not appear on the brink of default (near the solid line; the default boundary for the corresponding pure equity firm). 
Figure 19: Default, liquidation and renegotiation boundaries when debt holders offer

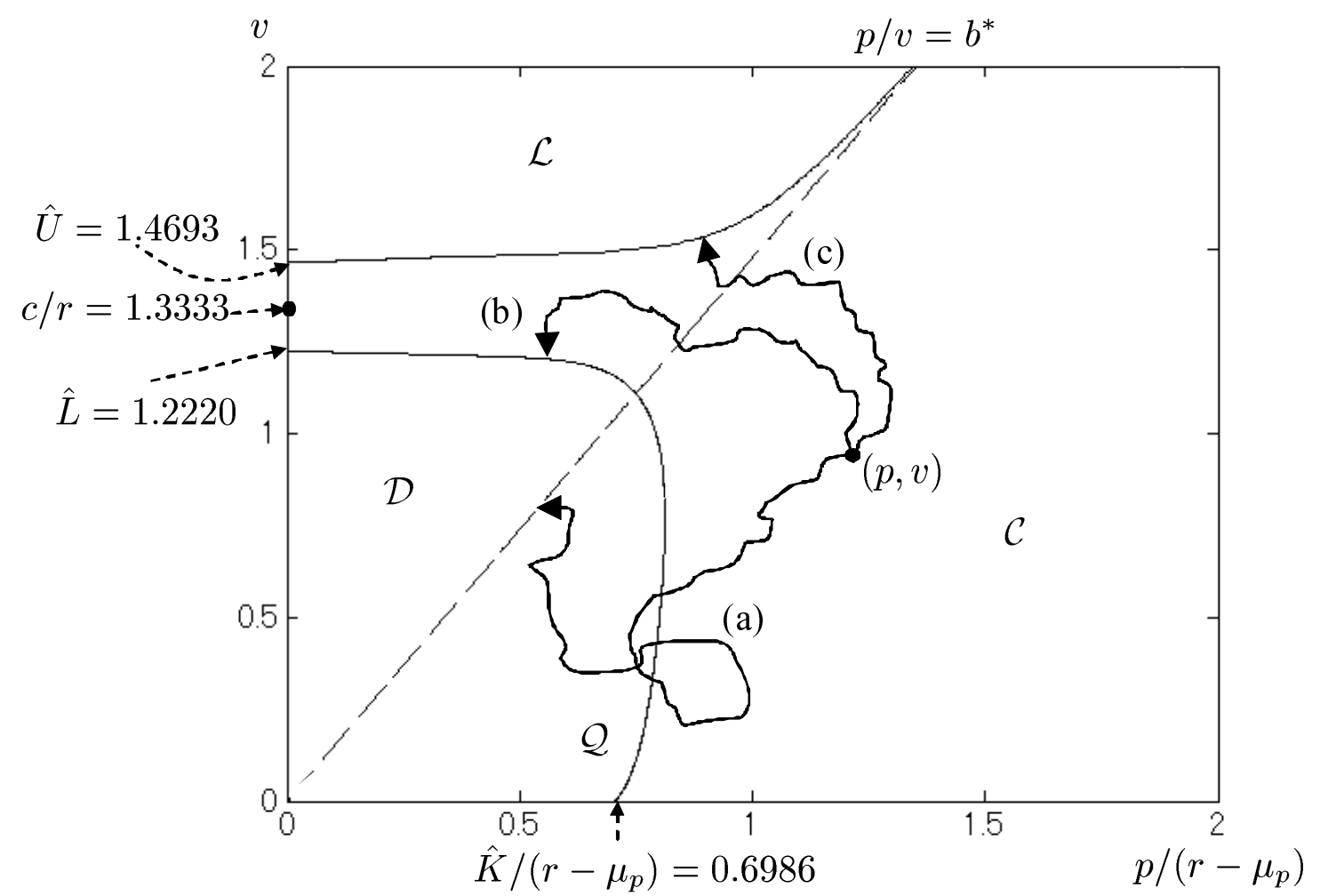

$\mathcal{L}$ denotes the liquidation region, $\mathcal{D}$ the default region, $\mathcal{C}$ the operating region, and $\mathcal{Q}$ the region for renegotiation by debt holders. The renegotiation region $\mathcal{Q}$ is given by $\hat{\mathcal{D}} \cap\left\{p / v>b^{*}\right\}$. The other regions coincide with those in Figure 1. The dashed line represents the straight line $p / v=b^{*}$. The parameters are taken from Table 1. Typical sample paths (a)-(c) are added to explain the renegotiation/default/liquidation mechanism in this case. 